\title{
A data assimilation system combining CryoSat-2 data and hydrodynamic river models
}

Schneider, Raphael; Ridler, Marc-Etienne; Godiksen, Peter Nygaard; Madsen, Henrik; Bauer-Gottwein, Peter

Published in:

Journal of Hydrology

Link to article, DOI:

10.1016/j.jhydrol.2017.11.052

Publication date:

2017

Document Version

Peer reviewed version

Link back to DTU Orbit

Citation (APA):

Schneider, R., Ridler, M-E., Godiksen, P. N., Madsen, H., \& Bauer-Gottwein, P. (2017). A data assimilation system combining CryoSat-2 data and hydrodynamic river models. Journal of Hydrology, 557, 197-210. https://doi.org/10.1016/j.jhydrol.2017.11.052

\section{General rights}

Copyright and moral rights for the publications made accessible in the public portal are retained by the authors and/or other copyright owners and it is a condition of accessing publications that users recognise and abide by the legal requirements associated with these rights.

- Users may download and print one copy of any publication from the public portal for the purpose of private study or research.

- You may not further distribute the material or use it for any profit-making activity or commercial gain

- You may freely distribute the URL identifying the publication in the public portal 


\section{Accepted Manuscript}

Research papers

A data assimilation system combining CryoSat-2 data and hydrodynamic river models

Raphael Schneider, Marc-Etienne Ridler, Peter Nygaard Godiksen, Henrik Madsen, Peter Bauer-Gottwein

PII: S0022-1694(17)30817-X

DOI: https://doi.org/10.1016/j.jhydrol.2017.11.052

Reference:

HYDROL 22410

To appear in:

Journal of Hydrology

Received Date: $\quad 27$ May 2017

Revised Date: $\quad 28$ November 2017

Accepted Date: $\quad 29$ November 2017

Please cite this article as: Schneider, R., Ridler, M-E., Godiksen, P.N., Madsen, H., Bauer-Gottwein, P., A data assimilation system combining CryoSat-2 data and hydrodynamic river models, Journal of Hydrology (2017), doi: https://doi.org/10.1016/j.jhydrol.2017.11.052

This is a PDF file of an unedited manuscript that has been accepted for publication. As a service to our customers we are providing this early version of the manuscript. The manuscript will undergo copyediting, typesetting, and review of the resulting proof before it is published in its final form. Please note that during the production process errors may be discovered which could affect the content, and all legal disclaimers that apply to the journal pertain. 


\section{A data assimilation system combining CryoSat-2 data and hydrodynamic river models}

Raphael Schneider ${ }^{\mathrm{a}}$, Marc-Etienne Ridler ${ }^{\mathrm{b}}$, Peter Nygaard Godiksen ${ }^{\mathrm{b}}$, Henrik Madsen $^{\mathrm{b}}$, Peter Bauer-Gottwein $^{\mathrm{a}}$

a) Technical University of Denmark, Department of Environmental Engineering,

Bygningstorvet, Building 115, 2800 Kgs. Lyngby, Denmark.

b) DHI, Agern Allé 5, 2970 Hørsholm, Denmark.

Corresponding author: Raphael Schneider (rasch@env.dtu.dk) 


\section{Abstract}

There are numerous hydrologic studies using satellite altimetry data from repeat-orbit missions such as Envisat or Jason over rivers. This study is one of the first examples for the combination of altimetry from drifting-ground track satellite missions, namely CryoSat-2, with a river model. CryoSat-2 SARIn Level 2 data is used to improve a 1D hydrodynamic model of the Brahmaputra River in South Asia, which is based on the Saint-Venant equations for unsteady flow and set up in the MIKE HYDRO River software. After calibration of discharge and water level the hydrodynamic model can accurately and bias-free represent the spatio-temporal variations of water levels. A data assimilation framework has been developed and linked with the model. It is a flexible framework that can assimilate water level data which are arbitrarily distributed in time and space. The setup has been used to assimilate CryoSat-2 water level observations over the Assam valley for the years 2010 to 2015, using an Ensemble Transform Kalman Filter (ETKF). Performance improvement in terms of discharge forecasting skill was then evaluated. For experiments with synthetic CryoSat-2 data the continuous ranked probability score (CRPS) was improved by up to $32 \%$, whilst for experiments assimilating real data it could be improved by up to $10 \%$. The developed methods are expected to be transferable to other rivers and altimeter missions. The model setup and calibration is based almost entirely on globally available remote sensing data.

Keywords: CryoSat-2; Data Assimilation; hydrodynamic models; satellite altimetry; rivers 


\section{Introduction}

Remote sensing provides valuable data for parameterization and updating of hydrologic models, for example water level measurements of inland water bodies from satellite radar altimeters. CryoSat-2, a Synthetic Aperture Radar (SAR) satellite launched by the European Space Agency (ESA) in April 2010, is a satellite mission primarily designed for the observation of the cryosphere (Wingham et al., 2006). Like other satellite altimeters, CryoSat2 also delivers useful altimetry data over inland water bodies. However, the unique orbit configuration of CryoSat-2 leads to a drifting ground track pattern, different from most other satellite altimetry missions. Nielsen et al. (2015) extracted water levels from lakes of a size down to $9 \mathrm{~km}^{2}$ from CryoSat-2 at higher accuracy than from any other current satellite altimetry mission: The RMSE between gauge data and the CryoSat-2 observed heights was generally below $10 \mathrm{~cm}$. Another example for the use of CryoSat-2 altimetry over lakes is the work by Song et al. (2015), who used CryoSat-2 in combination with ICESat altimetry to determine water level trends in Tibetan lakes. Water height estimation over rivers has high potential as well (Bercher et al., 2013b), as shown by Villadsen et al. (2015) and Schneider et al. (2017). Villadsen et al. (2016) estimated CryoSat-2 water level observations to be within approximately $30 \mathrm{~cm}$ of in situ observations at a station on the Amazon River. Another evaluation of the accuracy of CryoSat-2 observed river water levels against in situ observations was performed by Tourian et al., (2016). Their chosen method to transfer the altimetry observations to the locations of the in situ stations, however, was optimized for virtual station time series and not for the distributed CryoSat-2 data, not allowing for an independent evaluation of CryoSat-2 data. The potential of applying CryoSat-2 altimetry data 
over rivers is also stressed in a recent review of satellite data sources for surface waters by Musa et al. (2015).

Nevertheless, the application of CryoSat-2 altimetry over rivers is limited so far. This may be because CryoSat-2 challenges common ways of handling satellite altimetry data over inland water bodies, in particular rivers, as also described by Bercher et al. (2013a). All past and current satellite altimeter missions used in applications over rivers are on repeat orbits, returning to the same ground track every 10 (Jason-1 to Jason-3) to 35 days (Envisat or SARAL/AltiKa). The 91 day long repeat cycle of the laser altimeter mission ICESat is an exception. The spatial resolution, i.e. the inter-track distance also varies with the return cycle. The Jason missions with a return cycle of 10 days have an inter-track distance of approximately $315 \mathrm{~km}$ at the equator, while for Envisat or SARA/AltiKa it is around $80 \mathrm{~km}$. An overview of the characteristics of different satellite altimeter missions can be found in Schwatke et al. (2015) or in Jiang et al. (2017). For inland water bodies, in particular rivers, repeat orbits allow the extraction of water level time series at locations where the satellite ground track repeatedly intersects the water body, the so called virtual stations. The virtual stations are spaced with inter-track distance. CryoSat-2, with a repeat cycle of 369 days, does not deliver virtual station time series. However, it provides a higher spatial resolution along a river than other satellite altimetry missions - its inter-track distance at the equator is only $7.5 \mathrm{~km}$.

This means that CryoSat-2 can deliver water level profiles along rivers with much higher spatial resolution than the conventional short-repeat missions. The value of such dense data has been explored with other data sources than CryoSat-2: For example, O'Loughlin et al., 
2013 used data from ICESat with a relatively small inter-track distance of $30 \mathrm{~km}$ to derive hydraulic characteristics of the Congo River. Garambois et al., 2017 exploited spatially dense data from Envisat where its ground track coincidentally runs parallel with a river.

Using satellite altimetry data to update river models has proven to be successful. Paiva et al. (2013) assimilated Envisat altimetry data in a 1D hydrodynamic model of the entire Amazon River basin. This resulted in improvements of discharge simulations when validated against in situ data. For another large river, the Brahmaputra River in South Asia, Michailovsky et al. (2013) showed similar results, also with the assimilation of Envisat altimetry data to a Muskingum routing scheme. In operational use is the work by Hossain et al. (2014), using Jason-2 altimetry data to improve flood forecasting in the Ganges-Brahmaputra-Meghna Delta in Bangladesh. Besides this, there also exist numerous studies with synthetic data from the upcoming SWOT mission. This mission is expected to be launched in 2021. Biancamaria et al., (2016) provide a comprehensive overview over the expected applications of SWOT data for inland hydrology, including its assimilation into river models. Besides the studies presented therein, using ensemble based Kalman filters or smoothers, Gejadze and Malaterre (2016) developed a variational DA algorithm coupled for a 1D hydrodynamic model. All previous studies using actual data from operational missions, however, rely on altimetry data in the form of virtual stations. The main reason for this is that such time series allow deriving water level amplitudes (so called water surface elevation (WSE) anomalies), which are easier to assimilate than absolute water levels since any systematic bias between remote sensing observations and in-situ data is removed. CryoSat-2 data does not allow to directly derive water level amplitudes. The direct combination of such absolute water level data with models 
requires the model to accurately represent absolute water levels. To the best of our knowledge, no studies have yet assimilated CryoSat-2 altimetry in a river model, yet most of the setups developed for the uptake of synthetic SWOT data should also be able to be used with CryoSat-2 data.

There also do exist various ways of using altimetry data over rivers without directly combining them with a river routing model. For example, Boergens et al. (2016) presented a spatio-temporal kriging method to densify a multi-mission altimetry dataset along rivers. Also, discharge estimates over rivers have been performed based on satellite altimetry combined with other remote sensing data (Tarpanelli et al., 2015) or stochastic models (Tourian et al., 2017).

Different approaches can be used to model river flow: simple routing schemes such as the Muskingum and the Muskingum-Cunge schemes, 1D hydrodynamic models based on the Saint-Venant equations for unsteady flow, or 1D-2D models including the river flood plain. There is a trade-off between computational efficiency and realistic simulation of discharge routing, water levels and flood extents. Despite progress in computational efficiency of the 1D-2D hydrodynamic models and increased computational power available, most basin-scale applications of such models are still limited to deterministic simulations and do not support ensemble-based stochastic modelling and data assimilation (Biancamaria et al., 2011a, 2009; Schumann et al., 2013).

The objective of this work is to evaluate assimilation of distributed CryoSat-2 altimetry data in a $1 \mathrm{D}$ hydrodynamic model of the Brahmaputra River. This was done using a data 
assimilation (DA) system with ensemble based filters to update a DHI MIKE HYDRO River 1D hydrodynamic river model with water level data. Specifically, the proposed methods do not rely on (virtual) station observations, but are able to ingest water level (or discharge) data with arbitrary distribution in time and space. The 1D hydrodynamic model is mainly based on remote sensing data and allows accurate and unbiased simulations of water levels after a cross-section calibration (Schneider et al., 2017). Moreover, it is computationally efficient to be run with large ensembles for DA and model calibration. First, synthetic satellite data was assimilated to evaluate the general capability of the DA framework and the value of different data in controlled experiments. Subsequently, the model was updated by real water level observations from CryoSat-2.

\section{Brahmaputra River case study}

\subsection{Brahmaputra River overview}

The DA setup presented in this paper is demonstrated for the Brahmaputra River in South Asia. The Brahmaputra River is a large trans-boundary river, draining parts of the Tibetan Plateau in China before flowing through the Himalayan Mountains into the Assam Valley in India (Figure 1). It merges with the Ganges and Meghna Rivers in Bangladesh, before entering the Bay of Bengal. The river system often causes devastating floods in the low-lying downstream country Bangladesh. Despite this, there is only little cooperation between the river's three main riparian countries, China, India and Bangladesh (Biancamaria et al., 2011b). India considers the Brahmaputra basin "classified" (Central Water Commission, 2009) and hence no in situ data are publicly available. This shows the importance of remote 
sensing data to inform river models in the region, which is also reflected in the numerous studies for the region using remote sensing and specifically satellite altimetry data (for example Hossain et al. (2014); Michailovsky et al. (2013); Papa et al. (2015), (2010)).

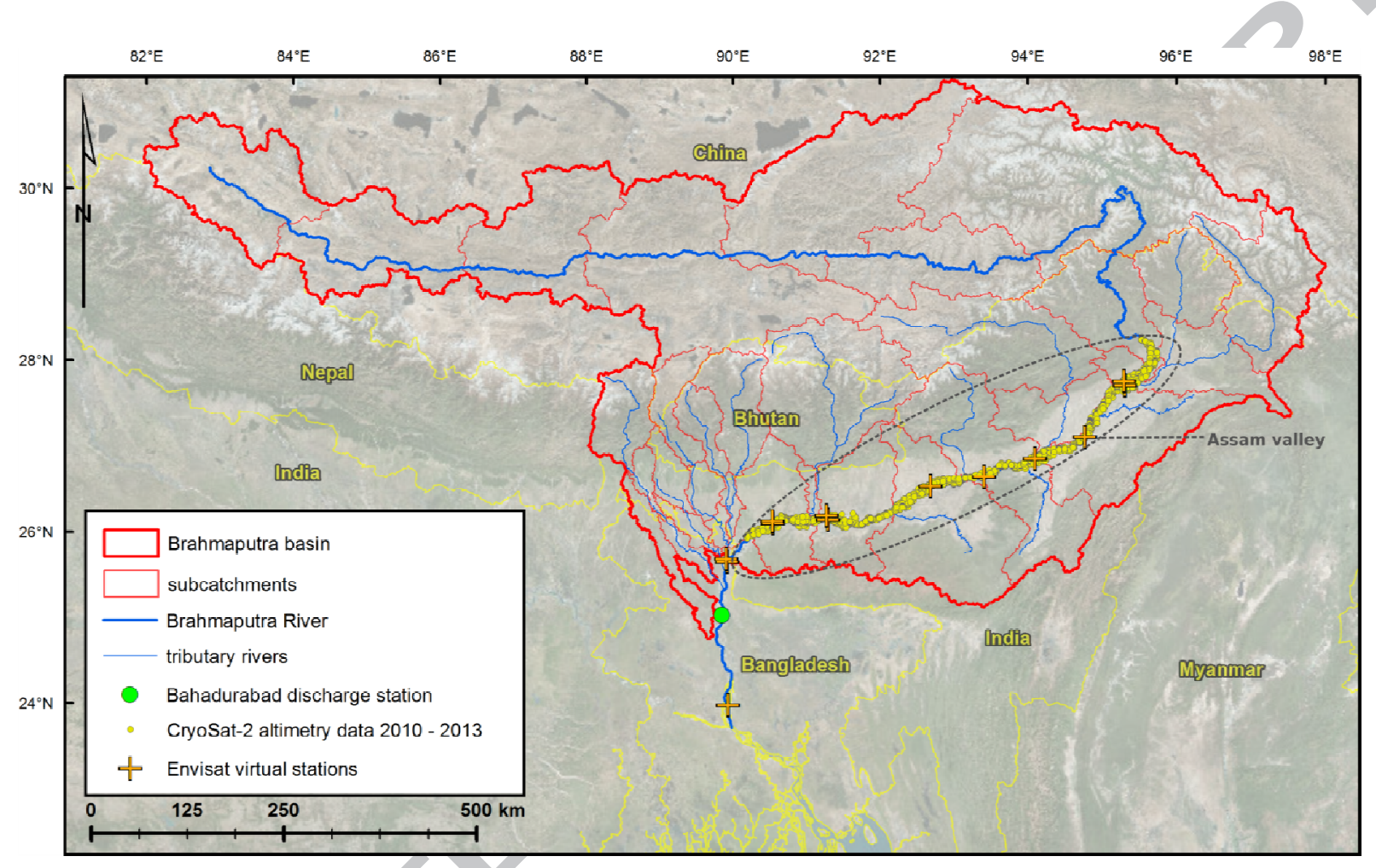

Figure 1: Base map of the Brahmaputra basin model. The focus of this work is the river reach in the Assam Valley, indicated in the map.

The model used in this study simulates the entire Brahmaputra basin. However, assimilation of altimetry data is limited to the downstream Assam valley, as sufficient amounts of satellite altimetry data are only available for this part of the river (data indicated in Figure 1). Here, the total floodplain width reaches up to $20 \mathrm{~km}$, and the single channels have a width up to a few hundred meters. Also, the surrounding terrain is relatively flat. Upstream of the Assam Valley, the Brahmaputra River flows through the Himalayan Mountains and the Tibetan Plateau and is more narrow and often confined by a steep river valley (Jain et al., 2007). 
CryoSat-2 adapts its range window, where it is sensitive to meaningful height measurements, in closed-loop control mode. This makes it hard, or impossible to obtain height observations over steep terrain (Dehecq et al., 2013). Also, most of the inland water satellite altimetry databases, such as HydroWeb (http://www.legos.obs-mip.fr/en/soa/hydrologie/hydroweb/), DAHITI (http://dahiti.dgfi.tum.de/en/), or River\&Lake (http://tethys.eaprs.cse.dmu.ac.uk/RiverLake/shared/main) do not offer any data for the upstream part of the Brahmaputra River. Only HydroSat (http://hydrosat.gis.unistuttgart.de/php/index.php) provides water levels for 12 virtual stations from Jason-2 along the upstream Brahmaputra River and its tributaries. However, CryoSat-2 provides a relevant amount of data (Schneider et al., 2017) also for the narrow upstream part of the Brahmaputra.

\subsection{Brahmaputra River hydrologic-hydrodynamic model}

The entire setup is based on the hydrologic-hydrodynamic modelling suite MIKE HYDRO River (previously MIKE 11, see DHI (2015)). The hydrodynamic model uses a 1D dynamic wave routing based on the Saint-Venant equations for unsteady flow (Havnø et al., 1995). A 6-point implicit finite difference scheme is used to solve the governing equations (Abbott and Ionescu, 1967). On a staggered grid of alternating $Q$ and $h$ points discharge is calculated at $Q$ points, whilst water level is calculated at $h$ points. Furthermore, the MIKE HYDRO River offers various rainfall-runoff models. Here the conceptual, lumped NAM rainfall-runoff model (Nielsen and Hansen, 1973) was used to generate the runoff forcing for the hydrodynamic model. 
This modelling framework was used to set up a hydrologic-hydrodynamic model of the Brahmaputra basin until Bahadurabad station, close to the Brahmaputra River's confluence with the Ganges River. The model is almost entirely based on globally available remote sensing data, because of restricted access to in situ data in the region. Model setup and calibration are described in detail in Schneider et al. (2017). The most important aspects are summarized in the following.

The focus of this work is the hydrodynamic part of the model, which was forced with simulated runoff from 33 subcatchments (Figure 1). The subcatchments are set up as NAM rainfall-runoff models, including snow melt modelling. Their precipitation forcing is derived from TRMM v7 3B42 data (Tropical Rainfall Measurement Mission Project (TRMM), 2011), and temperature and evaporation forcing are derived from the ERA-Interim reanalysis products from the European Centre for Medium-Range Weather Forecasts (ECMWF) (Dee et al., 2011).

Discharge calibration of the entire model was performed against in situ discharge from 2002 to 2007 at Bahadurabad station close to the outlet of the model. Discharge data from the same station from 2010 to 2015 was also used for the DA experiments, and can be seen in Figure 2. Note that in situ observations exist only for the high-flow periods. The observations usually occur five times daily, at 06:00, 09:00, 12:00, 15:00, and 18:00h, resulting in 5156 observations in total, covering 1067 individual days for the period 2010 to early 2015. DA experiments with real data thus could only be evaluated for the high-flow season. 


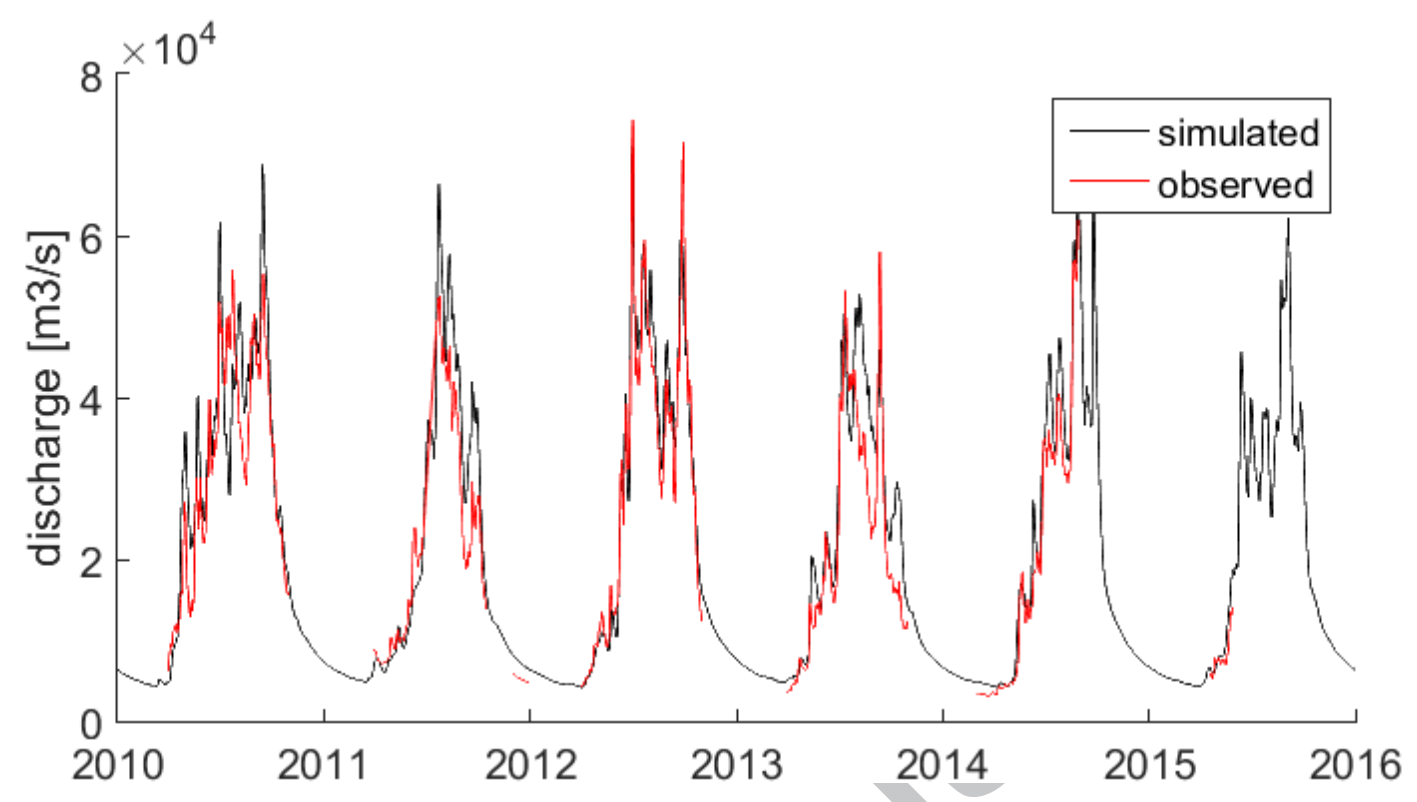

Figure 2: Observed and simulated discharge at Bahadurabad station for the years 2010 to 2015, i.e. the years covered by CryoSat-2 data. The initial model calibration period was 2002 to 2007.

Due to the lack of high precision DEM or bathymetry data, a cross-section calibration was performed. Synthetic, triangular cross-sections were placed at regular intervals. The crosssection opening angles and datums were calibrated so that simulated water level amplitudes matched observed amplitudes from Envisat virtual stations (indicated in Figure 1), and the simulated water level profile along the river matched the one observed by CryoSat-2, see details in Schneider et al. (2017). The resulting cross section shapes do not bear direct resemblance with the multi-channeled real river; their main purpose is to accurately simulate water level-discharge relationships. 


\section{CryoSat-2 altimetry data}

\subsection{Mission overview}

The CryoSat- 2 data used in this study are water levels from Level 2 data provided by the National Space Institute, Technical University of Denmark. The data are based on the ESA baseline-b Level 1b $20 \mathrm{~Hz}$ product (https://earth.esa.int/web/guest/-/how-to-access-cryosatdata-6842), and retracked with an empirical retracker (Jain et al., 2015; Villadsen et al., 2015). SIRAL, the main instrument on CryoSat-2, is a Ku-band radar altimeter. Most of the Brahmaputra basin is covered in the Synthetic Aperture Radar Interferometric (SARIn) mode of CryoSat-2, providing the possibility for off-nadir correction of the measurements' ground locations due to the second antenna. The footprint size in SARIn mode is rectangular with side lengths of approximately $1.65 \mathrm{~km}$ and $305 \mathrm{~m}$ for the across-track and the along-track direction, respectively (European Space Agency and Mullard Space Science Laboratory, 2012). The combination of a relatively small footprint and the detection of the main echo location in across-track direction in SARIn mode also means that hooking effects to water bodies (see e.g. Maillard et al. (2015)) cannot be exploited as for classical, larger footprint altimeters (LRM mode). The height reference for the CryoSat-2 observations was the EGM08 geoid. It is common for satellite altimeters to show small, systematic biases in their height observations. Tourian et al. (2016), for example, provide an estimate of this bias for CryoSat2 over the Adriatic Sea. For our application, however, these small inter-mission biases can be ignored as we do not compare the absolute water heights to heights from any other sources. 


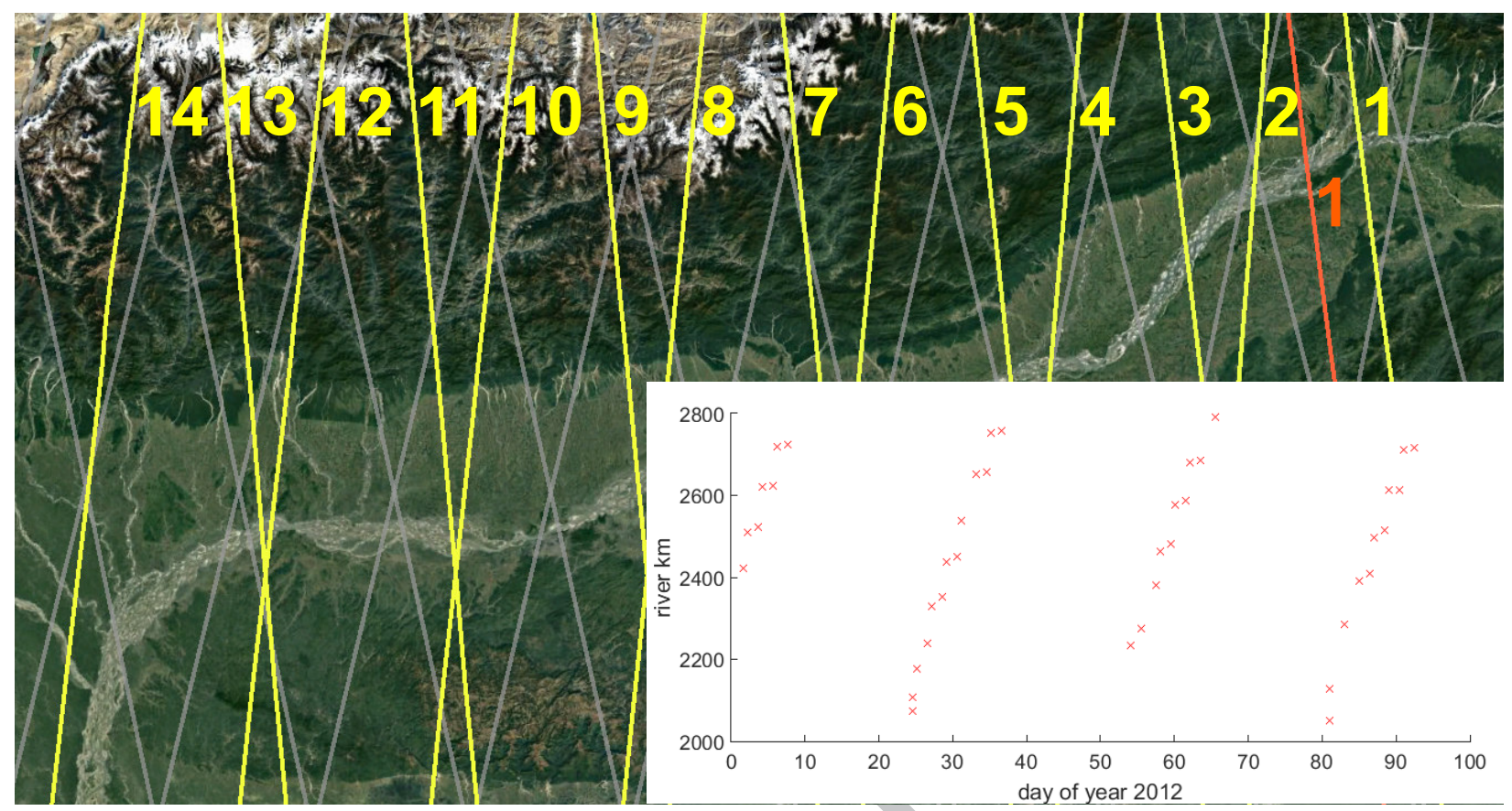

Figure 3: CryoSat-2 ground tracks over the Assam Valley. Displayed are tracks crossing the Brahmaputra River: 1 (yellow) being absolute orbit 17327, start time 13 July 2013 23:51 UTC, 1 (red) absolute orbit 17747, start time 13 August 2013 10:49 UTC. Envisat ground tracks are displayed in grey. The small panel shows the CryoSat-2 sampling pattern along the river chainage for the beginning of 2012. In terms of hydrologic applications, the main difference between CryoSat- 2 and all other previous and current altimetry missions is its drifting ground track pattern. CryoSat-2 usually will cross the approximately $800 \mathrm{~km}$ long stretch of the Brahmaputra River considered in this study 11 to 13 times for each of its 30-day sub-cycles. These crossings are numbered 1 to 13 in yellow (14 is not crossing the Brahmaputra) in Figure 3. Odd numbers indicate ascending orbits, even numbers descending orbits. The time between two consecutive crossings is on average 1 day ( $~ 0.5$ days between an ascending and a descending orbit, $\sim 1.5$ days between a descending and an ascending orbit). I.e. the river stretch in question will be sampled on average 12 times during a 12 day-window. This period is followed by approximately 18 days without observations. After 30 days a new sub-cycle, i.e. a new period with observations 
follows. For each sub-cycle the ground tracks are slightly shifted relative to the previous subcycle. This shift can be seen in Figure 3, where the red " 1 " indicates the first orbit of the subcycle following the yellow one. This gives a very different sampling pattern compared to conventional altimetry missions, such as Envisat. Its ground tracks, indicated in grey in Figure 3, give observations every 35 days at locations where they intersect with the river.

\subsection{Masking and aggregation of data}

To determine CryoSat-2 data points representing river water level, the observations have been filtered over yearly updated river masks derived from Landsat NDVI imagery. These river masks represent yearly minimum water extent to account for annual changes in river morphology, but cannot account for seasonal variations due to limitations from cloud cover. See Schneider et al. (2017) for details.

After filtering, each crossing of CryoSat-2 over the river usually consists of several individual data points. For DA purposes, observations from individual crossings are aggregated. Each crossing represents, at least in terms of the hydrodynamic model, the exact same time. In case of the satellite ground track crossing the river (nearly) perpendicularly, as is often the case for the predominantly east-west flowing Brahmaputra River in the Assam Valley, this means that all data points from one crossing can be aggregated into one measurement. In other cases, however, as shown in Figure 4, the satellite does cover a river stretch of considerable length with one crossing. Consequently, a different aggregation method has to be applied: Each river crossing is evaluated individually using a k-means clustering approach. First, the maximum spacing between individual data points of the current crossing (dots in Figure 4) along the 
river is determined. The number of clusters is determined by dividing the maximum spacing by a threshold distance ( $5 \mathrm{~km}$ in Figure 4; $1.5 \mathrm{~km}$ and $3 \mathrm{~km}$ were also tested). The individual data points are then grouped into the clusters by k-means clustering of their location (different colors represent different groups in Figure 4). Their location and observed water level is averaged (tilted crosses in Figure 4), and then projected onto the model river line (crosses).

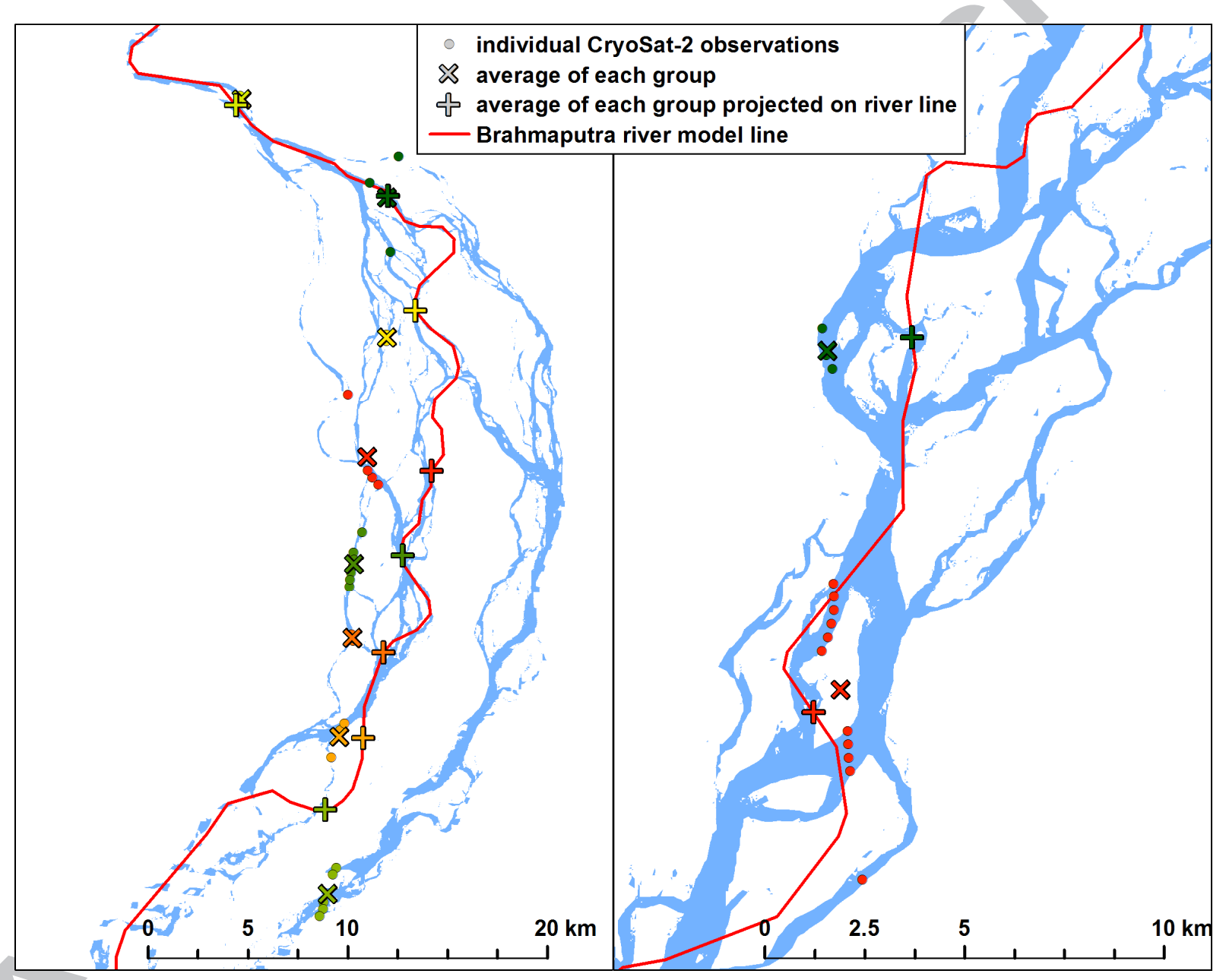

Figure 4: Clustering CryoSat-2 data from single crossings. The different colors indicate different groups. Left: crossing from 9 April 2011. Right: crossing from 30 October 2010. 
Assuming that all points of such a group represent the same river water level, the standard deviation of each group's individual point water levels can be used as an indicator of the related observation uncertainty.

\section{Data Assimilation setup}

This section starts with a general introduction to data assimilation (section 4.1), and then presents the DA framework used in this study, along with the specific setup and parameters used for the case study (sections 4.2 and 4.3). Section 4.4 describes how the setup of the synthetic DA experiments, and finally section 4.5 discusses the used DA verification measures.

\subsection{Data Assimilation introduction}

In general, DA refers to the updating of model forecasts with observations to minimize model prediction uncertainty. We consider a sequential updating of the model forecast in the following way

$$
\mathbf{x}_{t}^{a}=\mathbf{x}_{t}^{f}+\mathbf{K}_{t}\left(y_{t}-\mathbf{H}\left(\mathbf{x}_{t}^{f}\right)\right)
$$

where $\mathbf{x}_{t}$ is the current state of the model represented by its state vector. $\mathbf{x}_{t}^{f}$ is the model forecast propagated from the state at the previous time step according to the model dynamics (often referred to as model operator). Each time an observation becomes available, the forecast $\mathbf{x}_{t}{ }^{f}$ is updated using the observation $y_{t}$. This step results in the analysis state vector $\mathbf{x}_{a}{ }^{t}$. For the analysis, the gain operator $\mathbf{K}$ weighs between the model's forecast and the observation depending on the related uncertainties and correlations between state variables. 
$\mathbf{H}$ is the observation operator relating the model states to the observations. In our case, the model's state is represented by the state vector consisting of the water levels in the $h$ points described in the previous section, i.e. only the hydrodynamic part of the model is updated, not the rainfall-runoff models. In principle, both $h$ and $Q$ points of the model (compare section 2.2) can be included in the state vector. However, when including the $h$ points in the state vector only, the respective $Q$ values still get updated implicitly by the numerical model (Madsen and Skotner, 2005). In tests with the Brahmaputra model, this leads to very similar results than including both $Q$ and $h$ points.

Commonly, some implementation of the Kalman Filter (for example Jazwinski (1970); Maybeck (1979)) is used to perform the analysis in equation (1) and propagate the model's uncertainties. The classic Kalman Filter, however, requires an explicit calculation of the covariance matrix of the model state, limiting its use to linear models of relatively low order. Various approaches have been developed to circumvent these limitations, many of them based on ensemble methods. In ensemble filters, the covariance matrix is determined from an ensemble of model realizations representing the model state uncertainty.

For our case, the Ensemble Transform Kalman Filter (ETKF) has been used (Bishop et al., 2001), which is based on Ensemble Kalman Filter (EnKF) theory (Evensen, 2003). In ensemble filters, the covariance matrix $\mathbf{P}$ is estimated from the model ensemble (in the following the time index is omitted for clarity)

$$
\mathbf{P}=\frac{1}{m-1} \sum_{i=1}^{m}\left(\mathbf{X}_{i}-\mathbf{x}\right)\left(\mathbf{X}_{i}-\mathbf{x}\right)^{T}=\frac{1}{m-1} \mathbf{A} \mathbf{A}^{T}
$$


where $\mathbf{X}=\left[\mathbf{X}_{1}, \ldots, \mathbf{X}_{m}\right]$ is the ensemble of model states with size $m . \mathbf{x}=\frac{1}{m} \sum_{i=1}^{m} \mathbf{X}_{i}$ is the ensemble mean. $\mathbf{A}=\left[\mathbf{A}_{1}, \ldots, \mathbf{A}_{m}\right], \mathbf{A}_{i}=\mathbf{X}_{i}-\mathbf{x}$ are the ensemble anomalies. In the ETKF (Sakov and Oke, 2008), the ensemble mean is updated using equation (1). The ensemble anomalies are updated explicitly using

$$
\mathbf{A}^{a}=\mathbf{A}^{f} \mathbf{T}
$$

where $\mathbf{T}$ must satisfy

$$
\mathbf{T}=\mathbf{T}^{S} \mathbf{U}
$$

and

$$
\mathbf{T}^{S}=\left[I+\frac{1}{m+1}\left(\mathbf{H A}^{f}\right)^{T} \mathbf{R}^{-1} \mathbf{H} \mathbf{A}^{f}\right]^{-1 / 2}
$$

and $\mathbf{U}$ is an arbitrary orthonormal matrix, and $\mathbf{R}$ the observation error covariance matrix.

The ETKF was chosen over the also commonly used EnKF because the EnKF requires perturbing the assimilated observations. The ETKF does not require this as it updates the ensemble anomalies explicitly, which theoretically should lead to better filter results. Hence, the ETKF also has been shown to outperform the EnKF (Sakov and Oke, 2008). For details on the ETKF please refer to Sakov and Oke (2008).

\subsection{Data Assimilation framework}

The DA experiments were carried out with the DHI Data Assimilation Framework (adapted from Ridler et al. (2014)). Written in .NET/C\# it is integrated with MIKE HYDRO River, allowing various DA methods to be run with the hydrodynamic model. The DA framework 
provides different filters, error models and observation mapping methods to assimilate different datasets to MIKE models.

Configuration details are provided by the user through a specially formatted configuration file. The framework provides different filtering algorithms such as the Ensemble Kalman Filter (EnKF) and the Ensemble Transform Kalman Filter (ETKF). It includes bias-aware filtering, allowing measurement or model biases to be estimated by the filter (Ridler et al., 2014). Localization approaches are provided; that is the state updating can be restricted to model states in the neighborhood of the observation location. This is useful to avoid artefacts created by spurious correlations across the model space (Evensen (2009), chapter 15). The framework also provides different methods to describe model errors for the ensemble based filters. Auto-correlated errors of the forcing are integrated in the model state vector via state augmentation. By this a bias in the current model error description can be accounted for (see for example Evensen (2009) for a discussion of this).

For hydrologic-hydrodynamic models uncertainty often largely originates from simulated runoff, or originally from climate forcing uncertainty. The most important (and most uncertain) forcing for hydrologic models usually is precipitation. Hence, the runoff (or meteorological forcings of the rainfall-runoff models) has to be perturbed for model uncertainty description. This has been done in previous data assimilation studies: Andreadis et al. (2007) and Michailovsky et al. (2013) applied the error to the runoff generated by rainfallrunoff models, whilst others (Biancamaria et al., 2011a; Paiva et al., 2013) perturbed the precipitation (and temperature) forcing of the rainfall-runoff models. When using lumped rainfall-runoff models for a number of subcatchments, perturbation errors are expected to be 
both temporally and spatially correlated. A common approach to represent temporal correlation is a first-order autoregressive model (AR1)

$$
\mathbf{e}_{t}=\delta \mathbf{e}_{t-1}+\boldsymbol{\varepsilon}_{\mathrm{t}}
$$

where $\mathbf{e}_{t}$ is the vector of additive runoff perturbations for all subcatchments, $\delta$ the AR1

parameter, and $\boldsymbol{\varepsilon}_{t}$ a vector of white Gaussian noise with zero mean and standard deviation of $\sqrt{\left(1-\delta^{2}\right) a^{2}} \cdot a$ is a relative factor to scale the Gaussian noise. A Gaussian relative error was chosen as the relative discharge model error $\frac{Q_{\text {sin, },}-Q_{o b s, t}}{Q_{o b s, t}}$ at Bahadurabad station follows roughly a normal distribution. The noise was assumed spatially correlated, using the Cholesky decomposition $\mathbf{L}$ of the correlation matrix $\mathbf{C}$ (Kay, 1988, chap. 6)

$$
\boldsymbol{\varepsilon}_{t}=\boldsymbol{\varepsilon}_{t, u} \mathbf{L}
$$

where $\boldsymbol{\varepsilon}_{t, u}$ is the uncorrelated vector of noise, and $\boldsymbol{\varepsilon}_{t}$ the respective vector of spatially correlated noise used in equation (6). $\mathbf{C}$ describes the spatial (cross) correlation between the forcing perturbations of the different subcatchments. Finally the forcings are perturbed by

$$
\mathbf{f}_{p}=\mathbf{f}_{u}\left(1+\mathbf{e}_{t}\right)
$$

where $\mathbf{f}_{p}$ and $\mathbf{f}_{u}$ are the vectors of the perturbed and unperturbed forcings, respectively. To

avoid negative values and avoid introducing a bias for $\mathbf{f}_{p}, \mathbf{e}_{t}$ is truncated to ]-1; 1 [ by resampling.

In large models, correlations of state variables across the entire model state space are often not expected. However, such spurious correlations still can occur as a result of the limited 
ensemble size used to represent model uncertainty (Evensen, 2009, chap. 15). In such cases, localization has to be applied. In the DA framework, localization is implemented via the local analysis as described by Sakov and Bertino (2011), section 4. The basic principle of the local analysis is that it builds a virtual local window around each observation. This is implemented by scaling the observation covariance matrix with a taper function. The taper function scales the covariance matrix, usually with a value between 0 and 1 , effectively resulting in a full update where the value is 1 and no update where the value is 0 . In our case this taper function $f(r)$ was chosen to be a joined complementary error function $\operatorname{erfc}()$, used in the interval [0; 3]:

$$
f(r)=\left\{\begin{array}{lr}
s \cdot \operatorname{erfc}\left(\left(\frac{r}{r_{\max }}-0.5\right) 6\right) / 2 & \text { for } r<r_{\max } \\
0 & \text { otherwise }
\end{array}\right.
$$

where $r$ is the absolute distance along the river network from the observation location, and $r_{\max }$ a defined maximum distance for the local analysis (everything farther away will be disregarded for updating). The function is scaled to yield results between 0 and 1 by dividing it by two (further scaling can be applied via the factor $s$, which is set to 1 for the localization). The resulting function is displayed in Figure 5. The value of $f(r)$ describes a plateau around the observation point in the middle. With increasing distance it is smoothly approaching zero for $r=r_{\max }$. This shape was specifically chosen to guarantee smooth transitions between updated and not-updated states, which helps numerical stability of the hydrodynamic model. Furthermore, a wide plateau where the local analysis is applied fully is obtained. 


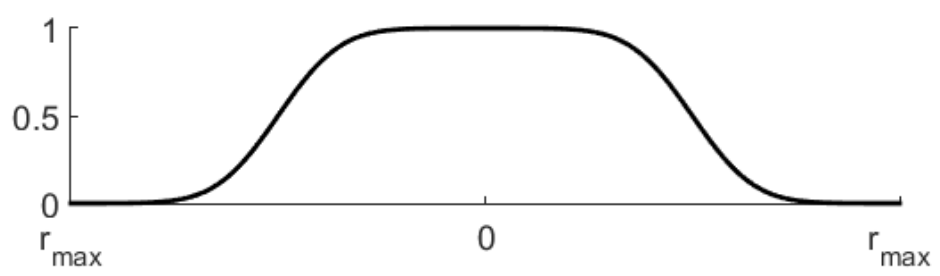

Figure 5: Two-sided complementary error function used to fade the localization in and out; see equation (9).

Hydrodynamic models usually have small simulation time steps, for example in the range of minutes. Often observations occur at much larger intervals, but in principle only would be assimilated at the single simulation time step closest to the observation. However, for many setups it is reasonable to assume that an observation delivers information about a longer time frame than a single simulation time step. Hence, virtual measurements are created by updating the model with the same observation at each simulation time step over a period defined as virtual window. This increases the system's memory for each observation, and allows for smoother updates preventing numerical instabilities in the model. To account for decreasing confidence in virtual measurements before and after the actual measurement and to smoothen the updating, the virtual measurements can be assimilated by scaling the observation uncertainty. This scaling can be done using the two-sided complementary error function in a modified additive form similar to equation (9). The impact of the fade in and out of the virtual window values however was shown to be small in this particular case. Hence, the given observation uncertainty was held constant over the entire virtual window in our application.

Extreme water level observations can be problematic for DA, because extreme updates can cause numerical instabilities or non-physical values in the hydrodynamic model. Hence, outliers have to be removed from the dataset. As an acceptable limit, a difference between 
simulated water levels and CryoSat-2 observations of $3 \mathrm{~m}$ was set. CryoSat-2 observations that deviated more than $3 \mathrm{~m}$ from the simulated water levels were either disregarded completely or their water level was changed to deviate only $3 \mathrm{~m}$ from the simulated water levels. The latter assumes that even though the CryoSat-2 observations are considered erroneous, they still deliver information on whether the true water levels are higher or lower than the simulated water levels. Both outlier treatments were tested in the following for the assimilation of real CryoSat-2 data.

\subsection{Data Assimilation parameters for Brahmaputra case}

The above described DA parameters have to be determined for the specific application.

For the description of the model uncertainty in the Brahmaputra model, the autocorrelation of the relative runoff error was assumed to be the same for all subcatchments and equal to the autocorrelation of the relative discharge model error $\frac{Q_{\text {sim }, t}-Q_{o b s, t}}{Q_{o b s, t}}$ at Bahadurabad station. The AR1 parameter based on those residuals was 0.96, and was used for the DA experiments. The magnitude of the relative runoff error at Bahadurabad station, however, was found to be too small to result in a realistic ensemble spread. Open loop experiments suggested a standard deviation for the Gaussian white noise in the range of 0.3: It was assumed that the coverage of the model ensemble (in terms of the $90 \%$ confidence intervals) should be around 0.9 . Like all other metrics, the coverage was evaluated against in situ discharge at Bahadurabad stations (see section 4.5). The spatial correlation of the forcing errors from the subcatchments was assumed to be the same as the spatial correlation of the simulated runoffs, and is in the range of 0.45 to 0.97 with a mean of 0.76 . 
An estimate of observation uncertainty was determined based on the clustered CryoSat-2 data as described in section 3.2. This procedure gives a good estimate of the uncertainties of the different observations relative to each other. For single observations or groups consisting of less than three individual observations a standard deviation of $1.5 \mathrm{~m}$ was assumed. Furthermore, a lower limit for the standard deviation of $0.1 \mathrm{~m}$ was applied. We assume that even if all measurements within one group closely agree, instrument and processing errors of CryoSat-2 observations are in that range (Pedersen (2016) and the references therein, Armitage and Davidson (2014); Wingham et al. (2006)).

Tests suggested a localization distance $r_{\max }$ of $200 \mathrm{~km}$ up- and downstream. Smaller values lead to more limited updates. Larger values sometimes lead to unreasonable updates due to spurious correlations in the limited-size model ensemble, causing the model to crash.

For the length of the virtual window $t_{v i r}$ a value of 120 minutes was used. The choice of this value was supported by an evaluation of the simulated water level dynamics. Simulated water level differences over different lag times, starting from 5 minutes, were evaluated. For lag times of 120 minutes the $95 \%$ quantile of changes in simulated water levels even during the high flow period is below $4 \mathrm{~cm}$.

Using the controlled synthetic DA experiment described in the following section, an optimal ensemble size was determined. For ensemble based Kalman Filters, the ensemble size should be chosen sufficiently large to reliably represent the full model uncertainty. However, it is also limited by computational restrictions. For a general discussion of this issue see for example Evensen (2009), chapter 11.7. In the context of hydrologic models see the discussion 
by Zhang et al. (2015) or DeChant and Moradkhani (2012). Often, an ensemble size below 100 is considered sufficient. However, this can vary from model to model. Hence, synthetic DA experiments with varying ensemble size were conducted. Based on this analysis, an ensemble size of 80 was considered a reasonable trade-off between computational effort and filter efficiency.

Details concerning the choice of the virtual window size and the ensemble size can be found in the supplementary material.

\subsection{Synthetic altimetry Data Assimilation experiments}

To test and evaluate the DA framework, controlled synthetic DA experiments were performed. This was done with the actual Brahmaputra basin model and synthetically extracted observations, in hidden truth experiments.

The synthetic observations were derived from a hidden truth run of the Brahmaputra basin model. The hidden truth is a run of the model with one random realization of the forcing perturbation that was also used to generate the ensemble for the description of the model uncertainty in the DA. This hidden truth run then displays significantly different discharge and water levels than the original model with unperturbed forcings (see synthetic truth and deterministic runs in Figure 7). From the simulated water levels of this hidden truth run, synthetic observations were extracted. To assess the value of CryoSat-2 observations when assimilated to the hydrodynamic model, the actual sampling pattern of CryoSat-2 was kept; that is the synthetic observations were extracted at the exact same points in time and location where real CryoSat-2 observations occur. To account for observation uncertainty, the 
synthetic observations were perturbed with Gaussian white noise. Standard deviations of both $0.2 \mathrm{~m}$ and $0.4 \mathrm{~m}$ were tested, as well as the observation error estimated from the clustering of the real observations as described in section 3.2. Finally, the synthetic observations were assimilated in the original model. The resulting discharge at Bahadurabad produced by the DA run was compared to the discharge from the hidden truth model. A flow chart displaying the whole procedure is shown in Figure 6.

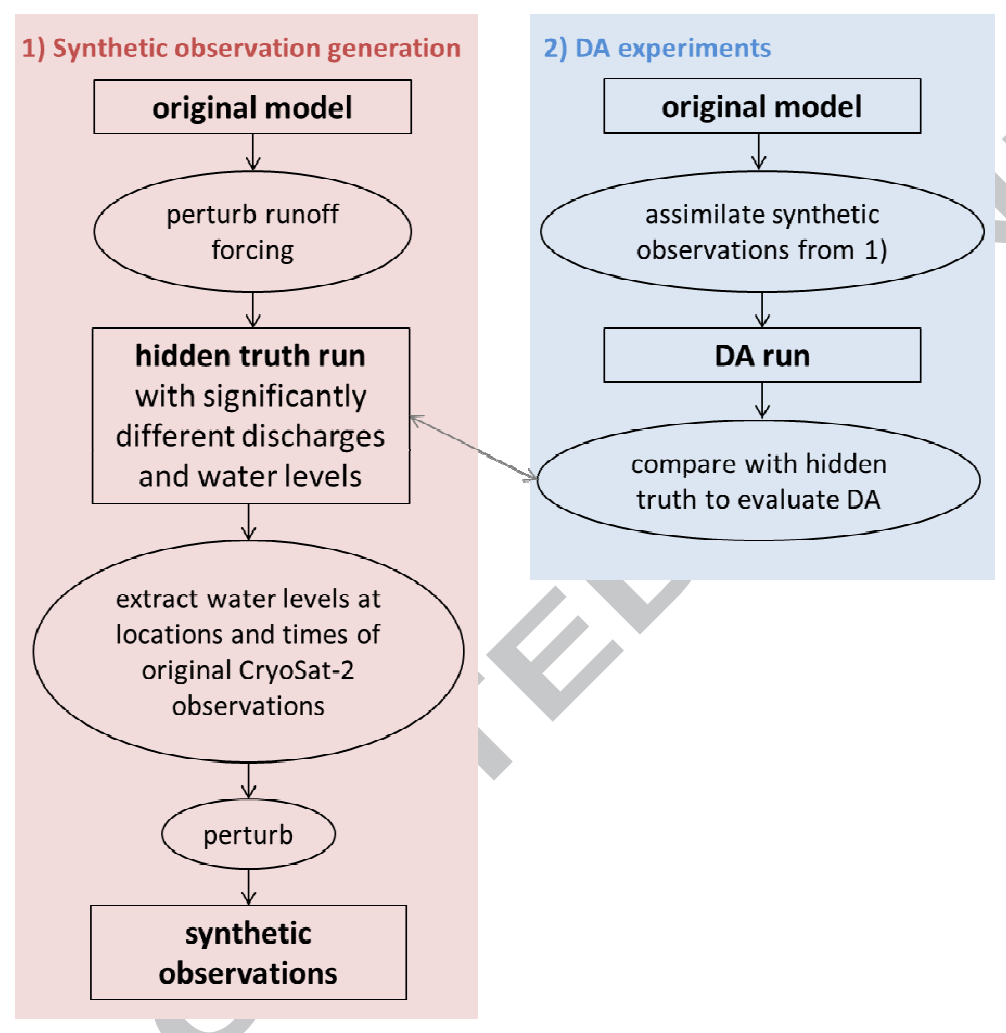

Figure 6: Flow chart displaying the hidden truth generation and following synthetic DA experiments

During each of the approximately 12 day long windows with CryoSat-2 observations over the Brahmaputra River described in section 3.1, the observations move downstream along the river with an approximate velocity of $0.7 \mathrm{~m} / \mathrm{s}$. Visual inspection of the model results showed that the simulated flood waves travelled with a velocity of approximately $1.5 \mathrm{~m} / \mathrm{s}$. Hence, 
flood waves in the Brahmaputra River, as in most rivers flowing from east to west, will overtake the ground track drift of CryoSat-2. The question then arises whether the sampling pattern of CryoSat-2 in relation to the river flow affects the updating of a hydrodynamic model of the river with CryoSat-2 data. To test this, another synthetic experiment was conducted. The setup was the same as described above, except that the temporal sequence of the observations was reversed. Practically this means that ground track drift and flow direction now are opposite to each other; or, in other words, this results in a sampling pattern as it would occur over a river flowing from west to east.

As mentioned, the developed DA framework is able to ingest altimetry data with any kind of spatio-temporal distribution. This ability was shortly tested with synthetic data from the ESA Sentinel-3A (launched in February 2016) and Sentinel-3B (scheduled to be launched in 2017) missions (ESA Earth Online, 2016). The identical Sentinel-3 missions are on a sunsynchronous orbit with a repeat cycle of 27 days; similar to other short-repeat missions such as Envisat or SARAL/AltiKa. The phase of Sentinel-3B's orbit is shifted by $+/-180^{\circ}$ to Sentinel-3A (Sentinel-3 Team, 2013). The ground tracks of Sentinel-3B fall directly in between those of Sentinel-3A. Sentinel-3 serves as an example for short-repeat missions providing virtual station data, to evaluate the impact of sampling pattern on data value in the DA. Other than for CryoSat-2 data, only theoretical ground tracks were available, and no actual sampling pattern. For each crossing of the theoretical ground track with the river line, one synthetic water level observations was extracted. Again, those extracted water levels were disturbed with white noise. 


\subsection{Data Assimilation verification measures}

The ensemble predictions of discharge from the DA experiments were evaluated using the continuous ranked probability score (CRPS) (Gneiting et al., 2005), a popular verification tool for probabilistic forecasts or model simulations.

$$
C R P S=\frac{1}{T} \sum_{t=1}^{T} \int_{-\infty}^{\infty}\left(F_{f, t}(Q)-F_{o, t}(Q)\right)^{2} d Q
$$

where $F_{f, t}$ is the empirical cumulative distribution function of the ensemble predictions at time $t$, and $F_{o, t}$ the respective empirical cumulative distribution function of the observation or synthetic truth. The CRPS combines reliability and sharpness of forecasts in one indicator; the theoretic optimum is zero. Furthermore, for deterministic simulations it simplifies to the mean absolute error (MAE). The ensemble predictions also were evaluated in terms of their coverage and sharpness. The prediction ranges are characterized by their $90 \%$ confidence intervals. Coverage describes the share of observations that fall within the range of predictions (i.e. the expected value is $90 \%$ ), and the sharpness is the width of this range, where smaller values are considered better. Another indicator is the commonly used NashSutcliffe model efficiency coefficient (NSE).

$$
N S E=1-\frac{\sum_{t=1}^{T}\left(Q_{f, t}-Q_{o, t}\right)^{2}}{\sum_{t=1}^{T}\left(Q_{o, t}-\overline{Q_{o}}\right)^{2}}
$$

where $Q_{f, t}$ and $Q_{o, t}$ are the simulated and observed discharge at time $t$, and $\overline{Q o}$ the mean of observed discharge. The NSE is an indicator for deterministic simulations; its values range from 1 (perfect model output) to negative infinity, where 0 indicates that the model output is as good as the mean of observations. When calculating the NSE of ensemble predictions, the 
ensemble mean was used. Furthermore, the root mean square error (RMSE) and bias were evaluated:

$$
\begin{aligned}
& \text { RMSE }=\sqrt{\frac{\sum_{t=1}^{T}\left(Q_{f, t}-Q_{o, t}\right)^{2}}{n}} \\
& \text { bias }=\frac{\sum_{t=1}^{T} Q_{f, t}-Q_{o, t}}{\sum_{t=1}^{T} Q_{o, t}}
\end{aligned}
$$

\section{Results and discussion}

\subsection{CryoSat-2 data}

Over the years 2010 to 2015, a total of 4553 single CryoSat-2 observations were obtained over the Brahmaputra River in the Assam Valley (Table 1). Observations from the same crossings were aggregated into groups as described in section 3.2. The resulting number of clustered observations is also shown in Table 1 for different cluster threshold distances. All values are shown separately for the low-flow (November to March) and high-flow period (April to October). Not surprisingly, the number of observations does not differ significantly between the two periods - this is because it was only possible to obtain one river mask for each year (see also Schneider et al. (2017) for a discussion of this), without distinguishing between different flow regimes. Numbers are still reported separately, as the in situ data used as benchmark in the DA experiments only cover the high-flow period; see Figure 2. Note that the CryoSat-2 mission started providing data in July 2010, and the used dataset ends in midFebruary 2015, when ESA baseline-b processing ended. 
Table 1: Number of CryoSat-2 observations over the Brahmaputra River in the Assam Valley. Single observation points and observations aggregated with different cluster distances are shown. Low-flow (lf) refers to November to March, high-flow (hf) to April to October. Values in brackets are outliers deviating more than $3 \mathrm{~m}$ from simulated water levels.

\begin{tabular}{|c|c|c|c|c|c|c|c|c|}
\hline & \multicolumn{2}{|c|}{ No. of single obs. } & \multicolumn{2}{|c|}{$\begin{array}{l}\text { No. of obs. with } \\
1.5 \mathrm{~km} \text { cluster } \\
\text { distance }\end{array}$} & \multicolumn{2}{|c|}{$\begin{array}{l}\text { No. of obs. with } 3 \mathrm{~km} \\
\text { cluster distance }\end{array}$} & \multicolumn{2}{|c|}{$\begin{array}{l}\text { No. of obs. with } 5 \mathrm{~km} \\
\text { cluster distance }\end{array}$} \\
\hline & If & hf & If & hf & If & hf & If & hf \\
\hline 2010 & $189(0)$ & $99(0)$ & 47 & 42 & 30 & 28 & 26 & 22 \\
\hline 2011 & $606(12)$ & $590(14)$ & 201 & 176 & 118 & 110 & 86 & 89 \\
\hline 2012 & $386(5)$ & $450(17)$ & 151 & 144 & 105 & 111 & 85 & 99 \\
\hline 2013 & $602(12)$ & $590(12)$ & 213 & 186 & 118 & 115 & 88 & 99 \\
\hline 2014 & $402(6)$ & $456(7)$ & 168 & 153 & 94 & 107 & 72 & 94 \\
\hline 2015 & $183(1)$ & $0(0)$ & 63 & 0 & 37 & 0 & 26 & 0 \\
\hline \multirow{2}{*}{ Sum } & $2368(36)$ & $2185(50)$ & 843 & 701 & 502 & 471 & 383 & 403 \\
\hline & \multicolumn{2}{|c|}{$4553(86)$} & \multicolumn{2}{|c|}{1544} & & & \multicolumn{2}{|c|}{786} \\
\hline
\end{tabular}

To determine the optimal cluster distance, one can for example evaluate the number of single observations per cluster. Using a distance of $1.5 \mathrm{~km}$ results in an average of 2.9 single observations per cluster. This means that there are many clusters with only 1 or 2 single observations, making an assessment of their uncertainty hard. Making the cluster distance too large, however, increases the error from assuming that all observations within one group should represent the same water level, while in reality they do not due to water level slope. As a trade-off, the $3 \mathrm{~km}$ cluster distance was chosen to be used in the DA experiments, both to assimilate real CryoSat-2 data, and to extract and assimilate synthetic CryoSat-2 data. With $3 \mathrm{~km}$ cluster distance, the mean error for all clusters with 3 or more members is $0.31 \mathrm{~m}$, which compares well to studies evaluating satellite radar altimetry observation error against in situ data over rivers (Villadsen et al., 2016). 


\subsection{Assimilation of synthetic CryoSat-2 altimetry}

Three different noises for the synthetic observations were tested; white noise with $0.2 \mathrm{~m}$ and $0.4 \mathrm{~m}$ standard deviation, and white noise with variable standard deviations as determined by the observation clustering. Furthermore, two different hidden truth runs (HT 1 and HT 2) were compared, and the experiments were repeated for the Brahmaputra River hypothetically flowing in west-east direction. Table 2 summarizes the results:

Table 2: Results from the synthetic DA experiments in terms of discharge at Bahadurabad station. CRPS is calculated against the discharge of the hidden truth model. Sharpness and coverage in relation to the $90 \%$ confidence interval. NSE refers to the ensemble mean. Average of 4 runs in each row.

\begin{tabular}{|c|c|c|c|c|c|c|c|}
\hline & & $\begin{array}{c}\text { NSE } \\
{[-]}\end{array}$ & $\begin{array}{c}\text { bias } \\
{[-]}\end{array}$ & $\begin{array}{c}\mathbf{R M S} \\
\mathbf{E} \\
{\left[\mathbf{m}^{3} / \mathbf{s}\right]} \\
\end{array}$ & $\begin{array}{l}\text { CRPS } \\
{\left[\mathrm{m}^{3} / \mathrm{s}\right]}\end{array}$ & $\begin{array}{c}\text { sharpnes } \\
\mathbf{s} \\
{\left[\mathbf{m}^{3} / \mathbf{s}\right]} \\
\end{array}$ & $\begin{array}{c}\text { coverag } \\
\mathbf{e} \\
{[-]} \\
\end{array}$ \\
\hline \multirow{7}{*}{$\begin{array}{c}\text { HT } \\
1\end{array}$} & open loop & 0.753 & 0.092 & 8695 & 3793 & 15611 & 0.773 \\
\hline & DA, CryoSat-2, obs. error $0.2 \mathrm{~m}$ & 0.885 & 0.034 & 5937 & 2565 & 9439 & 0.651 \\
\hline & DA, CryoSat-2, obs. error $0.4 \mathrm{~m}$ & 0.869 & 0.034 & 6347 & 2722 & 9688 & 0.673 \\
\hline & DA, CryoSat-2, cluster obs. error & 0.864 & 0.020 & 6462 & 2761 & 11333 & 0.775 \\
\hline & DA, CryoSat-2, obs. error $0.2 \mathrm{~m}$, west-east flow & 0.913 & 0.013 & 5169 & 1996 & 8153 & 0.782 \\
\hline & DA, CryoSat-2, obs. error $0.4 \mathrm{~m}$, west-east flow & 0.909 & 0.012 & 5278 & 2082 & 8728 & 0.781 \\
\hline & DA, CryoSat-2, cluster obs. error, west-east flow & 0.884 & 0.014 & 5965 & 2476 & 10868 & 0.829 \\
\hline \multirow{9}{*}{$\begin{array}{c}\text { HT } \\
2\end{array}$} & open loop & 0.848 & -0.097 & 7769 & 3305 & 15611 & 0.839 \\
\hline & DA, CryoSat-2, obs. error $0.2 \mathrm{~m}^{*}$ & 0.909 & -0.084 & 6011 & 2265 & 9256 & 0.821 \\
\hline & DA, CryoSat-2, obs. error $0.4 \mathrm{~m}$ & 0.896 & -0.084 & 6407 & 2445 & 9733 & 0.811 \\
\hline & DA, CryoSat-2, cluster obs. error & 0.901 & -0.090 & 6257 & 2420 & 11602 & 0.878 \\
\hline & DA, CryoSat-2, obs. error $0.2 \mathrm{~m}$, west-east flow & 0.911 & -0.083 & 5949 & 2137 & 8267 & 0.812 \\
\hline & DA, CryoSat-2, obs. error $0.4 \mathrm{~m}$, west-east flow & 0.911 & -0.085 & 5947 & 2192 & 8683 & 0.808 \\
\hline & DA, CryoSat-2, cluster obs. error, west-east flow & 0.899 & -0.098 & 6329 & 2345 & 11304 & 0.891 \\
\hline & DA, Sentinel-3A, obs. error $0.4 \mathrm{~m}$ & 0.882 & -0.110 & 6483 & 2388 & 7888 & 0.746 \\
\hline & $\begin{array}{l}\text { DA, Sentinel-3A and Sentinel-3B, } \\
\text { obs. error } 0.4 \mathrm{~m}\end{array}$ & 0.899 & -0.097 & 6335 & 2182 & 6693 & 0.661 \\
\hline
\end{tabular}

The open loop run is a run of the model ensemble with the exact same description of model uncertainty as used in the DA experiments, but without assimilating any data. It can be seen as a benchmark of the model's performance and uncertainty without DA. Largest improvements can obviously be achieved when assimilating synthetic observations with 
lowest observation uncertainties. For synthetic data with a standard error of $0.2 \mathrm{~m}$, the performance improvement in terms of CRPS is $32 \%$ and $31 \%$ for hidden truth 1 and 2 , respectively. This value decreases to $26 \%$ - $28 \%$ for data with a standard error of $0.4 \mathrm{~m}$ or with the variable uncertainty. In general, sharpness of the model ensemble output increases when DA is applied. The relative performance improvements between hidden truth 1 and hidden truth 2 are very similar, even though the absolute deviation from the original model run is larger for hidden truth 1 . In theory, the coverage of the $90 \%$ confidence interval of the ensemble forecasts should be 0.9 . The coverage of the open loop runs is only 0.773 for hidden truth 1 and 0.839 for hidden truth 2 . This indicates that especially hidden truth 1 is a model realization that is particularly far away from the original model. This can happen despite the random nature of the perturbations applied; because the temporal correlation of the perturbation error is high.

Interestingly, the flow direction of the river in relation to the ground track drift has an impact on the results. For the west-east flowing river, improvements of CRPS are between $29 \%$ to $47 \%$, compared to $26 \%$ to $32 \%$ for the original setup. This is likely related to the sampling pattern: For the west-east flowing river, CryoSat-2 observations drift in opposite direction of river flow. This results in a better spatio-temporal sampling pattern of river flow: With the original ground tracks (compare Figure 3), the last observation of each sub-cycle occurs at the downstream end of the Assam Valley. Every following first observation after the period without observations occurs at the upstream end. Consequently, any flood waves in a period of $\sim 18$ days plus the flood wave travel time from the upstream to the downstream end will be missed. In the west-east flowing river the sampling pattern is different and leads to increased 
data value. Figure 7 shows the results in terms of discharge at Bahadurabad of one DA run with an observation standard error of $0.2 \mathrm{~m}$ for the original CryoSat-2 orbit for hidden truth 2 .
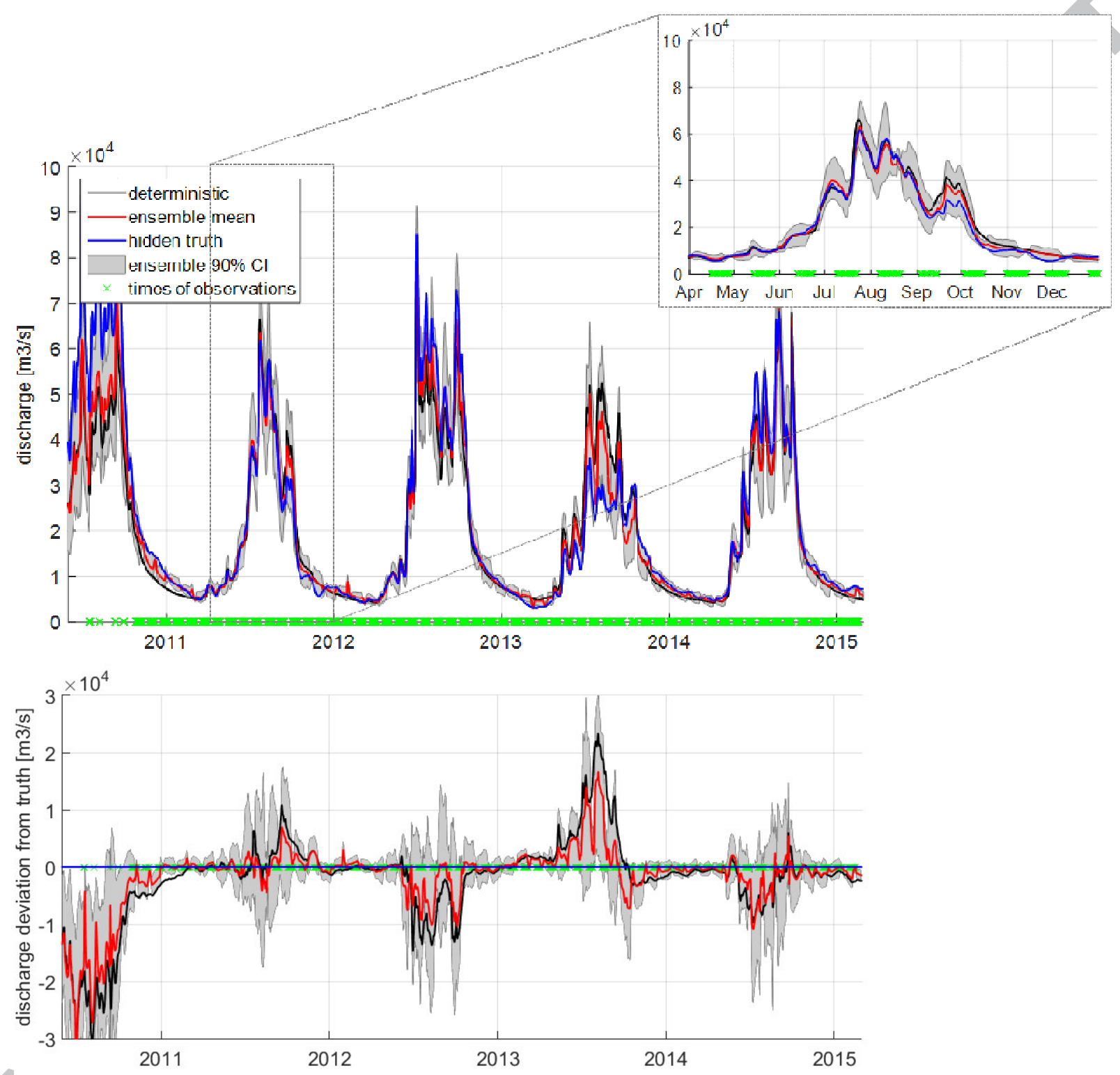

Figure 7: Results of DA of synthetic CryoSat-2 water level observations in comparison to the synthetic truth model results at Bahadurabad station. Example with hidden truth $\mathbf{2}$ and an observation error of $0.2 \mathrm{~m}$. The lower panel displays the deviations from the in situ data, as $Q_{\text {sim }}-Q_{\text {truth }}$ 


\subsection{Assimilation of synthetic Sentinel-3 altimetry}

Table 2 shows also the results of experiments with synthetic Sentinel-3A and Sentinel-3B data with an observation noise of $0.4 \mathrm{~m}$. For the given period, the Sentinel-3A dataset contains 754 synthetic observations, compared to 973 clustered observations with the used $3 \mathrm{~km}$ cluster distance from CryoSat-2 (Table 1). Even though the Sentinel-3A dataset offers fewer observations than CryoSat-2, the performance improvement is slightly larger. This is assumed to be related to the more regular sampling pattern of Sentinel-3A: the Brahmaputra River in the Assam Valley is observed at least every 3.5 days by Sentinel-3A, compared to up to 19 days without observations for CryoSat-2 (compare section 3.1). These long windows without observations allow the hydrodynamic model to deviate far from its updated state, as can for example be seen in the second half of September 2011 in Figure 7. Despite state augmentation of the forcing errors, the memory of the hydrodynamic model is shorter than the periods without observations. For a combination of Sentinel-3A and Sentinel-3B the number of synthetic observations increases to 1386, and the river is observed at least every 2 days. This gives further performance improvements.

\subsection{Assimilation of real CryoSat-2 altimetry}

For the real DA experiments, first tests were run assimilating all clustered CryoSat-2 observations. This included observations that deviated more than $3 \mathrm{~m}$ from the simulated water levels. As described in section 3.2, these observations were considered outliers. Two options to handle outliers were considered initally: i) Instead of removing them their water level was set to deviate by a maximum of $3 \mathrm{~m}$ (instead of more) from the simulated water 
levels. Their determined standard deviation was kept. ii) They were completely discarded, which lead to slightly better DA results. This indicates that information contained in these outliers on water levels being below or above simulated water levels does not add any value. Hence, the DA experiments discussed in the following and presented in Table 3 were conducted using the reduced dataset (Table 1 reports the number of such outliers). Other thresholds than the $3 \mathrm{~m}$ distance between simulated and observed water levels were tested as well. Except for extremely small thresholds discarding many observations and large thresholds leading to instabilities in the update step, the threshold value did not show to have a significant impact on DA performance.

Results for these runs, as discharge at Bahadurabad station, are shown in Table 3 and compared to climatology and persistence forecast results. Climatology and persistence are used as benchmarks as both can be produced easily: Climatology forecasts the current flow to be the average of the historic records on a specific day of year. Persistence forecasts the current flow to be equal to the previously observed flow (here from 1 to 7 days before). To begin with, already the open loop run performs significantly better than a climatology based on historic discharge data for the 45 years 1956 to 2000: coverage of the model ensemble forecast is slightly higher than of the climatology, and it is significantly sharper. This results also in a significantly better CRPS value. Also, persistence forecasts of more than 4 to 5 days are outperformed by the model's open loop run. 
Table 3: Results from the real DA experiments in terms of discharge at Bahadurabad station, compared to persistence and climatology forecasts, against in situ discharge observations. Sharpness and coverage given in relation to the $90 \%$ confidence interval.

\begin{tabular}{lcccccc} 
& NSE & bias & RMSE & CRPS \\
& {$[-]$} & {$[-]$} & $\begin{array}{c}\text { sharpness } \\
{\left[\mathbf{m}^{\mathbf{3}} / \mathbf{s}\right]}\end{array}$ & $\begin{array}{c}\text { coverage } \\
{\left[\mathbf{m}^{\mathbf{3}} / \mathbf{s}\right]}\end{array}$ & $\begin{array}{c}\left.\mathbf{m}^{\mathbf{3}} / \mathbf{s}\right] \\
{[-]}\end{array}$ \\
\hline Persistence (1 day) & 0.986 & 0.000 & 1851 & 1151 & - & - \\
Persistence (2 days) & 0.949 & 0.000 & 3475 & 2189 & - & - \\
Persistence (3 days) & 0.901 & 0.001 & 4855 & 3100 & - & - \\
Persistence (4 days) & 0.848 & 0.001 & 5998 & 3894 & - & - \\
Persistence (5 days) & 0.795 & 0.001 & 6935 & 4570 & - & - \\
Persistence (6 days) & 0.745 & 0.001 & 7704 & 5156 & - & - \\
Persistence (7 days) & 0.699 & 0.001 & 8338 & 5681 & - & - \\
\hline Climatology (based on 1956 -2000 data) & 0.651 & -0.137 & 9207 & 4775 & 20661 & 0.911 \\
\hline open loop & 0.839 & 0.110 & 6306 & 3332 & 15264 & 0.926 \\
\hline DA, base setup & 0.839 & 0.124 & 6311 & 3244 & 11405 & 0.834 \\
DA, scaled cluster obs. uncertainty by 0.5 & 0.842 & 0.119 & 6256 & 3245 & 10741 & 0.784 \\
DA, fixed obs. uncertainty 0.3 m & 0.871 & 0.094 & 5654 & 2997 & 9156 & 0.723 \\
DA, fixed obs. uncertainty 0.15 m & 0.874 & 0.086 & 5578 & 3021 & 8655 & 0.698
\end{tabular}

The DA base setup refers to a run assimilating all the CryoSat- 2 observations with 3 or more individual data points per cluster group, using their standard errors as an estimate of observation uncertainty. The effect of this assimilation run was small, resulting only in minor improvement of CRPS. Scaling these standard errors by a factor of 0.5 , consequently putting more trust in the observations does not provide better results either. Further experiments were conducted with a fixed observation uncertainty, instead of the varying uncertainties derived from the clustering. Here, more clear improvements could be shown. This indicates that the spread of individual data points is not a good estimator of the related observation uncertainty. Decreasing the observation uncertainty assumed in the DA from $0.3 \mathrm{~m}$ to $0.15 \mathrm{~m}$ showed no further improvement. Figure 8 shows the results in terms of discharge at Bahadurabad station for one run with a fixed observation uncertainty of $0.3 \mathrm{~m}$. It can be seen, especially in the detail showing April to December 2011, that updating the Brahmaputra hydrodynamic model with CryoSat-2 altimetry is improving the model's discharge prediction capabilities. The 
model uncertainty description was well chosen, as can be seen at the 0.926 coverage ratio of the $90 \%$ confidence intervals of the open loop run. The coverage, however, decreases significantly in the DA experiments; the more trust is put into the observations, the smaller the coverage. This can result from a discrepancy between the assimilated altimetry data and the in situ data used for verification, or also indicate that the model uncertainty is considered too low when assimilating data. Interestingly, except for the lowest observation uncertainty of $0.15 \mathrm{~m}$, the decrease in coverage is overcompensated by the increase in sharpness leading to a better CRPS value. 

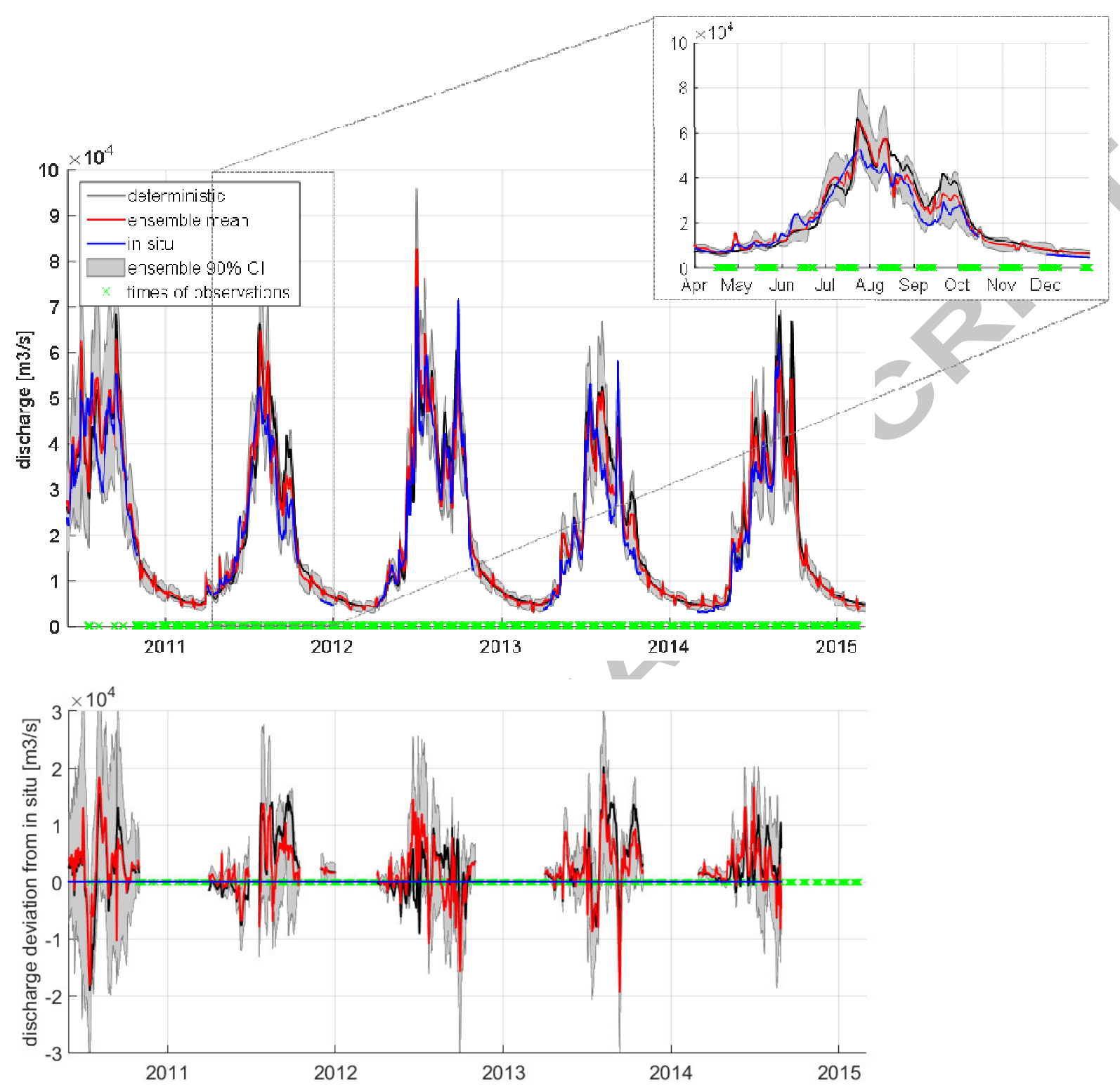

Figure 8: Results of DA of real CryoSat-2 water level observations in comparison to in situ data at Bahadurabad station. The lower panel displays the deviations from the in situ data, as $Q_{\text {sim }}-Q_{\text {in situ }}$

It has to be noted that the improvements obtained in the real DA experiments (up to $10 \%$ reduction in CRPS) are significantly smaller than those obtained in the synthetic DA experiments (up to $32 \%$ ). There are several possible reasons for this. For example, this behavior could indicate that the real CryoSat-2 observations have a lower accuracy than 
estimated by us. Ground validation over the Brahmaputra River, however, is not possible. In addition, the very sparse in situ data from Bahadurabad station may have inaccuracies. The simulated water level-discharge relationships are central to this problem, as the assimilation of water level observations are evaluated against observations of discharge. The simulated water level-discharge relationships are determined by the cross-section calibration (Schneider et al., 2017), which in itself is partly based on CryoSat-2 data. The uncertainties related to the cross-section calibration only affect the real DA experiments, not the synthetic ones. Such uncertainties related to model parameterization can be significant in this case. Further research could be directed towards an integration of channel parameters in the updated state vector. Besides this, the chosen model structure with triangular cross-sections and a uniform channel roughness might not be able to adequately represent river geometry and conveyance in this braided river under highly variable flow conditions. A general assessment of discrepancies between water levels simulated by a 1D hydrodynamic model and its satellite observations by Siddique-E-Akbor et al., 2011 found errors of up to $2.4 \mathrm{~m}$ over the Brahmaputra River.

Another potential reason for the limited DA performance is the CryoSat-2 data filtering. Using low-flow river masks only, it potentially misses a relevant amount of CryoSat-2 observations especially during the high-flow season. River masks at higher temporal resolution, allowing tracking intra-annual changes of water extent could be extracted from SAR imagery. Unlike optical imagery from Landsat or similar, SAR imagery can provide observations independently of cloud cover. Since mid-2014 there exists a source of freely available SAR imagery with high spatio-temporal resolution: ESA's Sentinel-1A mission. 
The model improvements that could be obtained here are comparable to similar large-scale satellite altimetry DA studies. As mentioned, however, those assimilated water level anomalies instead of absolute water levels. Michailovsky et al. (2013) improved the Interval Skill Score of simulated discharge by around $5 \%$ assimilating Envisat altimetry data from six virtual stations to a Muskingum routing model of the Brahmaputra River. This more simple model allowed to use the Extended Kalman Filter instead of ensemble methods. Assimilating Envisat altimetry data to a model of the Amazon River, Paiva et al. (2013) set up a model of the Amazon basin with very similar hydrologic-hydrodynamic structure as in this work. Assimilating Envisat data from 287 stations along the Amazon and its main tributaries using an EnKF, they managed to improve RMSE values of water levels compared to in situ observations by up to $44 \%$ and discharge by up to $15 \%$. Studies using synthetic SWOT data in various river model data assimilation setups (an overview can be found in Biancamaria et al., 2016) could show the significant value of the wide-swath SWOT data. However, only after a successful launch of the SWOT mission expected in 2021, such setups can be tested with real data.

\section{Conclusions}

A method to assimilate altimetry data with arbitrary spatio-temporal sampling pattern to a 1D hydrodynamic river model has been developed. Compared to many past applications of satellite altimetry data to river models it does not require satellite altimetry in form of virtual station data. This work is the first one to use absolute water levels from real observations distributed along the entire river's course instead of anomalies at virtual stations only. This is achieved by combining a hydrodynamic model able to simulate accurately and unbiased water 
levels (calibration procedure described in Schneider et al. (2017)) with a flexible DA framework. The method has been presented using drifting ground track CryoSat-2 altimetry data with a model of the Brahmaputra River basin. The CryoSat-2 data was filtered over dynamic river masks based on Landsat imagery and assimilated to a 1D hydrodynamic model in the MIKE HYDRO River software. CryoSat-2 data was extracted over the downstream Assam Valley of the Brahmaputra River, with a high spatial resolution sampling pattern.

The general capability of the developed DA framework in combination with the hydrodynamic model of the Brahmaputra River was demonstrated in controlled DA experiments with synthetic observations distributed as the original CryoSat-2 observations. Synthetic DA experiments showed improvements of discharge predictions at Bahadurabad station in terms of CRPS in the range of $26 \%$ to $32 \%$ compared to open loop runs. Also the influence of the river flow direction in relation to the ground track drift of CryoSat-2 was assessed, and it indicated that CryoSat-2's data has highest value for rivers flowing from west to east. The results show that altimetry with CryoSat-2's unique sampling pattern can significantly improve discharge simulations in river models. More regular sampling patterns without long periods lacking observations seem to have a beneficial impact on the results of the DA, as was shown by assimilating synthetic Sentinel-3 data. Potentially, updating model states with longer memory than the water levels in the hydrodynamic model, for example states of the rainfall-runoff models, could improve performance with such irregular sampling patterns.

Assimilating real CryoSat-2 data to the hydrodynamic model also proved to be successful. Discharge predictions of the model at Bahadurabad station, evaluated against the available in 
situ data for the high-flow season, could be improved by up to $10 \%$ in terms of CRPS. An estimate of the CryoSat-2 observations uncertainty was calculated in this study based on grouping individual data points. Using this estimate, however, did not improve the model's discharge predictions. Best results were obtained by assigning a fixed observation uncertainty to all outlier-removed observations.

Direct validation of CryoSat-2 observations over the Brahmaputra River is hard due to the very limited access to in situ observations. The limited data availability, however, also makes the use of remote sensing data crucial and useful in practice. Further studies could be performed over river basins with better in situ data availability. The positive results from assimilating the data to a hydrodynamic model nevertheless indicate the general validity of the CryoSat-2 altimetry data, the chosen model setup, and the developed DA framework. In addition, first results of validation of CryoSat-2 altimetry observations over rivers indicate performance comparable to other current altimetry missions, also over more narrow rivers such as the Po River (Tourian et al., 2016; Villadsen et al., 2016, 2015).

Because the developed model setup is based almost entirely on globally available remote sensing data, and the flexible DA approach can ingest any kind of altimetry data, the presented setup is expected to be transferable to almost any large river basin. Moreover, the flexible DA framework, in combination with the cross-section calibration procedure, opens the opportunity for assimilation of multi-mission datasets to hydrodynamic models. 


\section{Acknowledgements}

The work presented in this paper was partly funded by the LOTUS - Preparing Sentinel-3 SAR Altimetry Processing for Ocean and Land project, part of the European Union's Seventh Framework Programme for research, technological development and demonstration under grant agreement no. 313238; and the ESA Cryosat2 Success over Inland Water and Land (CRUCIAL) project, awarded under ITT ESRIN/AO/1-6827/11/I-NB. Within the LOTUS project, the CryoSat-2 data was kindly provided by the National Space Institute, Technical University of Denmark. The setup and calibration of the Brahmaputra model used in this study was carried out in collaboration with the International Centre for Integrated Mountain Development (ICIMOD).

\section{References}

Abbott, M.B., Ionescu, F., 1967. On The Numerical Computation Of Nearly Horizontal Flows. J. Hydraul. Res. 5, 97-117. doi:10.1080/00221686709500195

Andreadis, K.M., Clark, E.A., Lettenmaier, D.P., Alsdorf, D.E., 2007. Prospects for river discharge and depth estimation through assimilation of swath-altimetry into a rasterbased hydrodynamics model. Geophys. Res. Lett. 34, L10403. doi:10.1029/2007GL029721

Armitage, T.W.K., Davidson, M.W.J., 2014. Using the Interferometric Capabilities of the ESA CryoSat-2 Mission to Improve the Accuracy of Sea Ice Freeboard Retrievals. IEEE 
Trans. Geosci. Remote Sens. 42, 529-536. doi:10.1109/TGRS.2013.2242082

Bercher, N., Calmant, S., Picot, N., Seyler, F., Fleury, S., 2013a. Evaluation of Cryosat-2 Measurements for the Monitoring of Large River Water Levels, in: Ouwehand, L. (Ed.), Proceedings of 20 Years of Progress in Radar Altimetry. European Space Agency, Venice, Italy.

Bercher, N., Dinardo, S., Lucas, B.M., Fleury, S., Calmant, S., Crétaux, J.-F., Femenias, P., Boy, F., Picot, N., Benveniste, J., 2013b. Applications of CryoSat-2 SAR \& SARIn modes for the monitoring of river water levels, in: Proceedings of CryoSat Third User Workshop, 12 - 14 March 2013. Dresden, Germany.

Biancamaria, S., Bates, P.D., Boone, A., Mognard, N.M., 2009. Large-scale coupled hydrologic and hydraulic modelling of the Ob river in Siberia. J. Hydrol. 379, 136-150. doi:10.1016/j.jhydrol.2009.09.054

Biancamaria, S., Durand, M., Andreadis, K.M., Bates, P.D., Boone, A., Mognard, N.M., Rodríguez, E., Alsdorf, D.E., Lettenmaier, D.P., Clark, E.A., 2011a. Assimilation of virtual wide swath altimetry to improve Arctic river modeling. Remote Sens. Environ. 115, 373-381. doi:10.1016/j.rse.2010.09.008

Biancamaria, S., Hossain, F., Lettenmaier, D.P., 2011b. Forecasting transboundary river water elevations from space. Geophys. Res. Lett. 38, L11401. doi:10.1029/2011GL047290

Biancamaria, S., Lettenmaier, D.P., Pavelsky, T.M., 2016. The SWOT Mission and Its Capabilities for Land Hydrology. Surv. Geophys. 37, 307-337. doi:10.1007/s10712-015- 
9346-y

Bishop, C.H., Etherton, B.J., Majumdar, S.J., 2001. Adaptive Sampling with the Ensemble Transform Kalman Filter. Part I: Theoretical Aspects. Mon. Weather Rev. 129, 420-436. doi:10.1175/1520-0493(2001)129<0420:ASWTET>2.0.CO;2

Boergens, E., Buhl, S., Dettmering, D., Klüppelberg, C., Seitz, F., 2017. Combination of multi-mission altimetry data along the Mekong River with spatio-temporal kriging. J. Geod. 91, 519-534. doi:10.1007/s00190-016-0980-z

Central Water Commission, 2009. Integrated Hydrological Data Book (non-classified river basins). New Delhi.

DeChant, C.M., Moradkhani, H., 2012. Examining the effectiveness and robustness of sequential data assimilation methods for quantification of uncertainty in hydrologic forecasting. Water Resour. Res. 48. doi:10.1029/2011WR011011

Dee, D.P., Uppala, S.M., Simmons, A.J., Berrisford, P., Poli, P., Kobayashi, S., Andrae, U., Balmaseda, M.A., Balsamo, G., Bauer, P., Bechtold, P., Beljaars, A.C.M., van de Berg, L., Bidlot, J., Bormann, N., Delsol, C., Dragani, R., Fuentes, M., Geer, A.J., Haimberger, L., Healy, S.B., Hersbach, H., Hólm, E. V., Isaksen, L., Kållberg, P., Köhler, M., Matricardi, M., Mcnally, A.P., Monge-Sanz, B.M., Morcrette, J.J., Park, B.K., Peubey, C., de Rosnay, P., Tavolato, C., Thépaut, J.N., Vitart, F., 2011. The ERA-Interim reanalysis: Configuration and performance of the data assimilation system. Q. J. R. Meteorol. Soc. 137, 553-597. doi:10.1002/qj.828 
Dehecq, A., Gourmelen, N., Shepherd, A., Cullen, R., Trouvé, E., 2013. Evaluation of CryoSat-2 for height retrieval over the Himalayan range, in: Ouwehand, L. (Ed.), CryoSat-2 Third User Workshop. European Space Agency, Dresden, Germany.

DHI, 2015. MIKE 11 - A Modelling System for Rivers and Channels - Reference Manual. Hørsholm, Denmark.

ESA Earth Online, 2016. Sentinel-3 Mission Details [WWW Document]. URL https://earth.esa.int/web/guest/missions/esa-eo-missions/sentinel-3 (accessed 1.1.16).

European Space Agency, Mullard Space Science Laboratory, 2012. CryoSat Product Handbook.

Evensen, G., 2009. Data Assimilation - The Ensemble Kalman Filter, 2nd ed, Vasa. Springer, Berlin Heidelberg.

Evensen, G., 2003. The Ensemble Kalman Filter: theoretical formulation and practical implementation. Ocean Dyn. 53, 343-367. doi:10.1007/s10236-003-0036-9

Garambois, P.A., Calmant, S., Roux, H., Paris, A., Monnier, J., Finaud-Guyot, P., Samine Montazem, A., Santos da Silva, J., 2017. Hydraulic visibility: Using satellite altimetry to parameterize a hydraulic model of an ungauged reach of a braided river. Hydrol. Process. 31, 756-767. doi:10.1002/hyp.11033

Gejadze, I., Malaterre, P.-O., 2016. Discharge estimation under uncertainty using variational methods with application to the full Saint-Venant hydraulic network model. Int. J. Numer. Methods Fluids 601-629. doi:10.1002/fld.4273 
Gneiting, T., Raftery, A.E., Westveld, A.H., Goldman, T., 2005. Calibrated Probabilistic Forecasting Using Ensemble Model Output Statistics and Minimum CRPS Estimation. Mon. Weather Rev. 133, 1098-1118. doi:10.1175/MWR2904.1

Havnø, K., Madsen, M.N., Dørge, J., 1995. MIKE 11 - A Generalized River Modelling Package, in: Singh, V.P. (Ed.), Computer Models of Watershed Hydrology. Water Resource Publications, Highlands Ranch, CO, pp. 733-782.

Hossain, F., Maswood, M., Siddique-E-Akbor, A.H., Yigzaw, W., Mazumdar, L.C., Ahmed, T., Hossain, M., Shah-Newaz, S.M., Limaye, A., Lee, H., Pradhan, S., Shrestha, B., Bajracahrya, B., Biancamaria, S., Shum, C.K., Turk, F.J., 2014. A promising radar altimetry satellite system for operational flood forecasting in flood-prone Bangladesh. IEEE Geosci. Remote Sens. Mag. 2, 27-36. doi:10.1109/MGRS.2014.2345414

Jain, M., Andersen, O.B., Dall, J., Stenseng, L., 2015. Sea surface height determination in the Arctic using Cryosat-2 SAR data from primary peak empirical retrackers. Adv. Sp. Res. 55, 40-50. doi:10.1016/j.asr.2014.09.006

Jain, S.K., Agarwal, P.K., Singh, V.P., 2007. Brahmaputra and Barak Basin, in: Hydrology and Water Resources of India, Water Science and Technology Library. Springer Netherlands, Dordrecht, pp. 419-472. doi:10.1007/1-4020-5180-8_9

Jazwinski, A.H., 1970. Stochastic Processes and Filtering Theory, Mathematics in Science and Engineering. Academic Press.

Jiang, L., Schneider, R., Andersen, O., Bauer-Gottwein, P., 2017. CryoSat-2 Altimetry 
Applications over Rivers and Lakes. Water 9, 211. doi:10.3390/w9030211

Kay, S.M., 1988. Modern Spectral Estimation: Theory and Application. Prentice Hall.

Madsen, H., Skotner, C., 2005. Adaptive state updating in real-time river flow forecasting-a combined filtering and error forecasting procedure. J. Hydrol. 308, 302-312. doi:10.1016/j.jhydrol.2004.10.030

Maillard, P., Bercher, N., Calmant, S., 2015. New processing approaches on the retrieval of water levels in Envisat and SARAL radar altimetry over rivers: A case study of the São Francisco River, Brazil. Remote Sens. Environ. 156, 226-241. doi:10.1016/j.rse.2014.09.027

Maybeck, P.S., 1979. Introduction, Stochastic models, estimation, and control. Academic Press, New York, NY.

Michailovsky, C.I., Milzow, C., Bauer-Gottwein, P., 2013. Assimilation of radar altimetry to a routing model of the Brahmaputra River. Water Resour. Res. 49, 4807-4816. doi:10.1002/wrcr.20345

Musa, Z.N., Popescu, I., Mynett, A., 2015. A review of applications of satellite SAR, optical, altimetry and DEM data for surface water modelling, mapping and parameter estimation. Hydrol. Earth Syst. Sci. 19. doi:10.5194/hess-19-3755-2015

Nielsen, K., Stenseng, L., Andersen, O.B., Villadsen, H., Knudsen, P., 2015. Validation of CryoSat-2 SAR mode based lake levels. Remote Sens. Environ. 171, 162-170. doi:10.1016/j.rse.2015.10.023 
Nielsen, S.A., Hansen, E., 1973. Numerical simulation of the rainfall runoff process on a daily basis. Nord. Hydrol. 4, 171-190.

O’Loughlin, F., Trigg, M.A., Schumann, G.J.P., Bates, P.D., 2013. Hydraulic characterization of the middle reach of the Congo River. Water Resour. Res. 49, 5059-5070. doi:10.1002/wrcr.20398

Paiva, R.C.D., Collischonn, W., Bonnet, M.-P., de Gonçalves, L.G.G., Calmant, S., Getirana, A., Santos da Silva, J., 2013. Assimilating in situ and radar altimetry data into a largescale hydrologic-hydrodynamic model for streamflow forecast in the Amazon. Hydrol. Earth Syst. Sci. 10, 2879-2925. doi:10.5194/hess-17-2929-2013

Papa, F., Durand, F., Rossow, W.B., Rahman, A., Bala, S.K., 2010. Satellite altimeter-derived monthly discharge of the Ganga-Brahmaputra River and its seasonal to interannual variations from 1993 to 2008. J. Geophys. Res. 115, C12013. doi:10.1029/2009JC006075

Papa, F., Frappart, F., Malbeteau, Y., Shamsudduha, M., Vuruputur, V., Sekhar, M., Ramillien, G., Prigent, C., Aires, F., Pandey, R.K., Bala, S., Calmant, S., 2015. Satellitederived surface and sub-surface water storage in the Ganges-Brahmaputra River Basin. J. Hydrol. Reg. Stud. 4, 15-35. doi:10.1016/j.ejrh.2015.03.004

Pedersen, J.W., 2016. Assimilation of CryoSat-2 water heights to a Muskingum-Cunge routing scheme. Technical University of Denmark.

Ridler, M.-E., Madsen, H., Stisen, S., Bircher, S., Fensholt, R., 2014. Assimilation of SMOS- 
derived soil moisture in a fully integrated hydrological and soil-vegetation-atmosphere transfer model in Western Denmark. Water Resour. Res. 50, 8962-8981. doi:10.1002/2014WR015392

Sakov, P., Bertino, L., 2011. Relation between two common localisation methods for the EnKF. Comput. Geosci. 15, 225-237. doi:10.1007/s10596-010-9202-6

Sakov, P., Oke, P.R., 2008. Implications of the Form of the Ensemble Transformation in the Ensemble Square Root Filters. Mon. Weather Rev. 136, 1042-1053. doi:10.1175/2007MWR2021.1

Schneider, R., Godiksen, P.N., Villadsen, H., Madsen, H., Bauer-Gottwein, P., 2017. Application of CryoSat-2 altimetry data for river analysis and modelling. Hydrol. Earth Syst. Sci. 21, 751-764. doi:10.5194/hess-21-751-2017

Schumann, G.J.P., Neal, J.C., Voisin, N., Andreadis, K.M., Pappenberger, F., Phanthuwongpakdee, N., Hall, A.C., Bates, P.D., 2013. A first large-scale flood inundation forecasting model. Water Resour. Res. 49, 6248-6257. doi:10.1002/wrcr.20521

Schwatke, C., Dettmering, D., Bosch, W., Seitz, F., 2015. DAHITI - an innovative approach for estimating water level time series over inland waters using multi-mission satellite altimetry. Hydrol. Earth Syst. Sci. 19, 4345-4364. doi:10.5194/hess-19-4345-2015

Sentinel-3 Team, 2013. Sentinel-3 User Handbook.

Siddique-E-Akbor, A.H.M., Hossain, F., Lee, H., Shum, C.K., 2011. Inter-comparison study 
of water level estimates derived from hydrodynamic-hydrologic model and satellite altimetry for a complex deltaic environment. Remote Sens. Environ. 115, 1522-1531. doi:10.1016/j.rse.2011.02.011

Song, C., Ye, Q., Sheng, Y., Gong, T., 2015. Combined ICESat and CryoSat-2 altimetry for accessing water level dynamics of Tibetan lakes over 2003-2014. Water 7, 4685-4700. doi:10.3390/w7094685

Tarpanelli, A., Brocca, L., Barbetta, S., Faruolo, M., Lacava, T., Moramarco, T., 2015. Coupling MODIS and Radar Altimetry Data for Discharge Estimation in Poorly Gauged River Basins. IEEE J. Sel. Top. Appl. Earth Obs. Remote Sens. 8, 141-148. doi:10.1109/JSTARS.2014.2320582

Tourian, M.J., Schwatke, C., Sneeuw, N., 2017. River discharge estimation at daily resolution from satellite altimetry over an entire river basin. J. Hydrol. 546, 230-247. doi:10.1016/j.jhydrol.2017.01.009

Tourian, M.J., Tarpanelli, A., Elmi, O., Qin, T., Brocca, L., Moramarco, T., Sneeuw, N., 2016. Spatiotemporal densification of river water level time series by multimission satellite altimetry. Water Resour. Res. 52, 1140-1159. doi:10.1002/2015WR017654

Tropical Rainfall Measurement Mission Project (TRMM), 2011. Tropical Rainfall Measurement Mission Project (TRMM) 3-Hourly 0.25 deg. TRMM and Others Rainfall Estimate Data.

Villadsen, H., Deng, X., Andersen, O.B., Stenseng, L., Nielsen, K., Knudsen, P., 2016. 
Improved inland water levels from SAR altimetry using novel empirical and physical retrackers. J. Hydrol. 537, 234-247. doi:10.1016/j.jhydrol.2016.03.051

Villadsen, H., Andersen, O.B., Stenseng, L., Nielsen, K., Knudsen, P., 2015. CryoSat-2 altimetry for river level monitoring - Evaluation in the Ganges-Brahmaputra basin. Remote Sens. Environ. 168, 80-89. doi:10.1016/j.rse.2015.05.025

Wingham, D.J., Francis, C.R., Baker, S., Bouzinac, C., Brockley, D., Cullen, R., de ChateauThierry, P., Laxon, S.W., Mallow, U., Mavrocordatos, C., Phalippou, L., Ratier, G., Rey, L., Rostan, F., Viau, P., Wallis, D.W., 2006. CryoSat: A mission to determine the fluctuations in Earth's land and marine ice fields. Adv. Sp. Res. 37, 841-871. doi:10.1016/j.asr.2005.07.027

Zhang, D., Madsen, H., Ridler, M.E., Refsgaard, J.C., Jensen, K.H., 2015. Impact of Model Uncertainty Description on Assimilating Hydraulic Head in the MIKE SHE Distributed Hydrological Model. Adv. Water Resour. 86, 400-413.

doi:10.1016/j.adywatres.2015.07.018 
One of the first hydrologic applications of drifting-orbit altimetry from CryoSat-2

Flexible data assimilation framework developed for of multi-mission altimetry data

Data assimilation experiments with CryoSat-2 data over Brahmaputra River model 